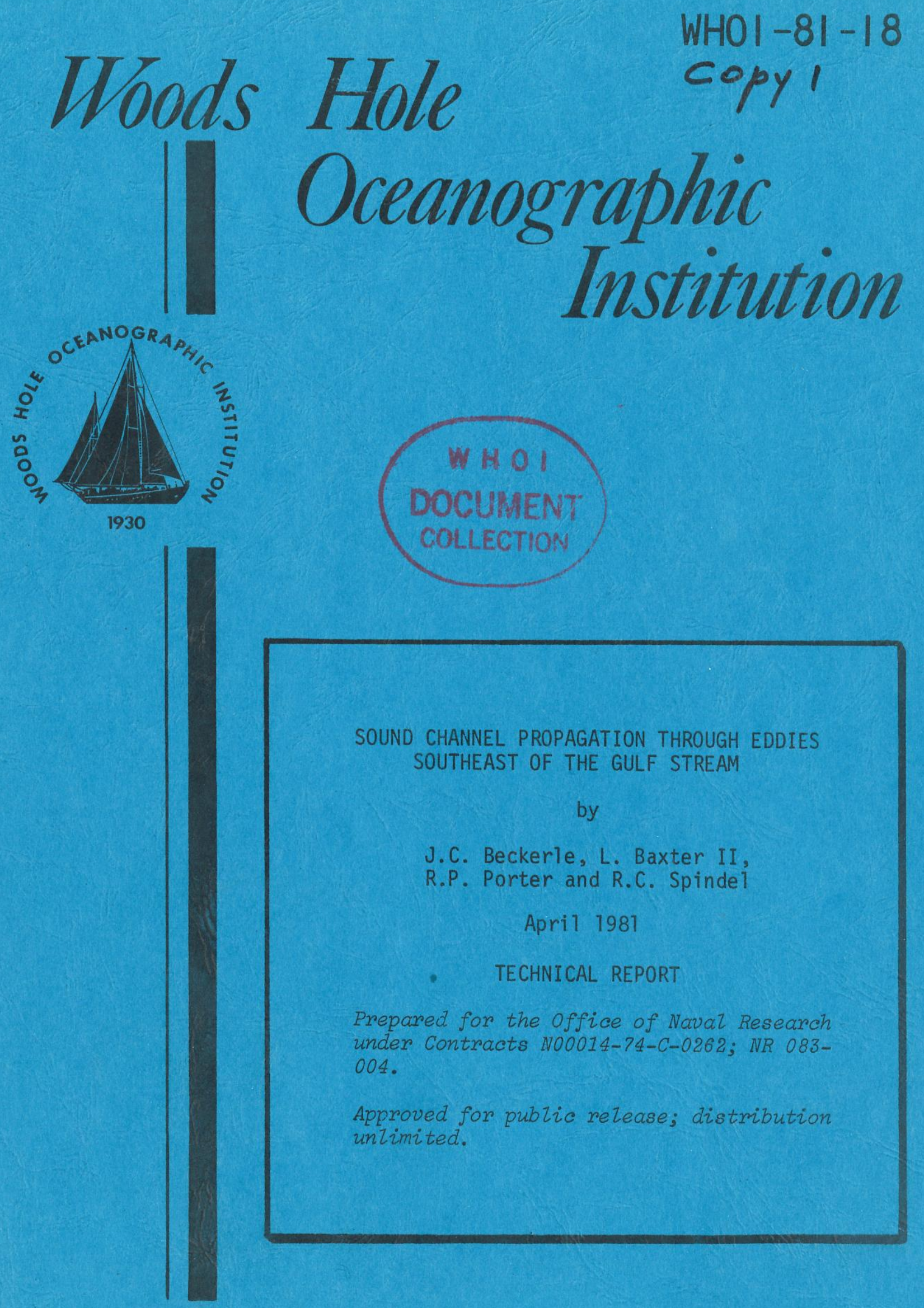

IVOODS HOLE, MASSACHUSETTS 02543 


\title{
WHOI-81-18
}

\section{SOUND CHANNEL PROPAGATION THROUGH EDDIES SOUTHEAST OF THE GULF STREAM}

by

J.C. Beckerle, L. Baxter II, R.P. Porter and R.C. Spindel

\author{
WOODS HOLE OCEANOGRAPHIC INSTITUTION \\ Woods Hole, Massachusetts 02543
}

Apri1 1981

\section{TECHNICAL REPORT}

Prepared for the Office of Naval Research under Contract N00014-74-C-0262; NR 083-004.

Reproduction in whole or in part is permitted for any purpose of the United States Govermment. In citing this report in a bibliography, the reference given should be to: J.Acoust. Soc. Am. 68 (6): 1750-1767, (December 1980).

Approved for public release; distribution unlimited.

Approved for Distribution: Earl E. Hays, Chairman Department of Ocean Engineering 


\title{
Sound channel propagation through eddies southeast of the Gulf Streama)
}

\author{
J. C. Beckerle, ${ }^{\text {b) }}$ L. Baxter, II, R. P. Porter, ${ }^{\text {c) }}$ and R. C. Spindel \\ Woods Hole Oceanographic Institution, Woods Hole, Massachusetts 02543 \\ (Received 11 April 1979; accepted for publication 3 September 1980)
}

\begin{abstract}
Acoustical signals at $270 \mathrm{~Hz}$ from SOFAR floats drifting in the region southeast of the Gulf Stream were recorded during most of 1975 from a near axis sound channel hydrophone near Bermuda. The amplitude levels received exhibit a large increase (12-18 dB) commencing about $24 \mathrm{July}$, following a long period (March to July) of relatively lower peak level amplitudes. A major part of the increase can be attributed to the influence of a large cyclonic eddy (Gulf Stream ring) that passed slowly between the SOFAR floats and Bermuda. Such an eddy produces a large sound speed anomaly that extends to depths below the axis of the sound channel. On 24 July, two SOFAR floats were known to have approximately the same sound transmission path through the edge of the large eddy. The sound transmission peaks occur when no ocean eddy is between the SOFAR floats and the receiver. Their spacing shows they occur at regular refraction caustics in the sound channel. When the sound transmission path passes through an eddy, these transmission focal distances are shifted to greater range and the signal level may be greatly enhanced. The decrease of caustic peak intensities with range is $5 \mathrm{~dB}$ per double distance, and this agrees with theory. Several different levels of peak acoustic intensity occur and these result from two float depths and oceanic thermocline oscillations.
\end{abstract}

PACS numbers: $43.30 . \mathrm{Bp}, 92.10 . \mathrm{Vz}, 93.30 . \mathrm{Mj}$

\section{INTRODUCTION}

In 1970, Rossby and Webb ${ }^{1}$ began a prog ram to measure currents in the ocean at about the depth of the minimum in sound speed $(\sim 1200 \mathrm{~m})$ by acoustic tracking of neutrally buoyant SOFAR floats. The floats emit acoustic pulses which are received on distant hydrophones in the main sound channel. The position of each float is determinedby acoustic triangulation. A few years later, during the midocean dynamics experiment in the Sargasso Sea, south of Bermuda, numerous SOFAR floats were tracked by Rossby et al. (1975), ${ }^{2}$ and Freeland et al. (1975). ${ }^{3}$ Acoustic fluctuations of the sounds from thesefloats were studied by Baxter and Yang (1974). ${ }^{4}$

In late 1974, under ONR sponsorship, the U.S. Naval Oceanographic Office with the cooperation of the Woods Hole Oceanog raphic Institution, launched ten SOFAR floats southeast of the Gulf Stream to determine whether some would become trapped for a while within intense eddies (cold rings) that break away from the Gulf Stream. The rings are formed from la rge southern meanders of the Gulf Stream that encircle cold water from the north side of the stream near the latitude of the New England seamounts. After the meander breaks free from the main Gulf Stream, there is a strong cyclonic (counter clockwise) flow with a cold water center characterized by a large upward displacement of the isotherms, hence the nomenclature "cold rings." The analysis and interpretation of the acoustic signals from three SOFAR floats through Gulf Stream rings are presented here.

It is known that several eddies of varying intensity and size exist simultaneously southeast of the Gulf Stream, and some have life times of $2 \mathrm{yr}$. Cheney et al. $(1976)^{5}$ present a description of the SOFAR float

\footnotetext{
${ }^{a)}$ Contribution No. 4333 .

b) Now with Scientific Applications Research Associates SARA: 38 Two Ponds Road, Falmouth, MA 02540.

c) Now with Schlumberger-Doll Research Center, Ridgefield, CT 06877 .
}

tracks and eddies found in 1974. Some of the floats were trapped in eddies for a few months and two were caught up in the Gulf Stream. While some of these SOFAR floats were tracked through 1975, an extensive seagoing effort including aircraft sea temperature surveys was underway to study the properties of Gulf Stream eddies and their motions.

In March 1975, automatic recording equipment was used to obtain recordings of the acoustic signals from three of these SOFAR floats on a hydrophone in the sound channel through the rest of the year. Any explanation of the acoustic data presented here would be impossible without the extensive study of eddy locations and motions as well as tracking of the SOFAR float positions that took place in 1975 . We are particularly grateful to R. Cheney of NAVOCEANO who supplied almost all of these data.

\section{ACOUSTICAL MEASUREMENTS}

The three SOFAR floats, numbers 1,2 , and 4 were launched about $200 \mathrm{NM}$ northwest of Bermuda from 10 October to 30 October 1974 at depths 1080, 1050, and $1290 \mathrm{~m}$, respectively. Due to creep in the cylinder walls of the neutrally buoyant floats, they slowly sink, $0.5 \mathrm{~m}$ per day, so that their nominal depths during the acoustical measurements from March to December 1975 were: Number 1,1140-1290 m; number 2, 1110$1260 \mathrm{~m}$; and number 4, 1350-1500 m. Numbers 1 and 2 were at the depth of the minimum of the sound speed profile in this ocean region (Sargasso Sea water), whereas SOFAR float 4 was a little below the depth of the minimum. Float 4, however, is well inside the depth range of the deep sound channel.

The SOFAR floats emitted a $270-\mathrm{Hz}$ tone for $24 \mathrm{~s}$ every $6 \mathrm{~h}$. The floats could be identified in the received signal by the specific $\frac{1}{2}-\mathrm{h}$ window in which they emitted their pulse. The data acquisition system recorded the float signals on digital magnetic tape cassettes. The input signal to the equipment from a hydro- 
phone within the sound channel was bandpass filtered at $270 \mathrm{~Hz}$ to reduce noise. It was then mixed with a 270$\mathrm{Hz}$ local oscillator and the resulting sum and difference signal was smoothed with a $\frac{1}{2}-\mathrm{Hz}$ low-pass filter. A continuous series of digital amplitude values of the output every $\frac{1}{2} \mathrm{~S}$ was recorded on magnetic tape. The continuously recorded series of digital amplitude values is proportional to the component of the input signal that is in phase with the local oscillator. Unfortunately, only one quadrature component of the signal was recorded. Therefore the resultant time series can be positive, negative or zero depending on the relative phase of the input signal and the local oscillator. Thus, even when a strong SOFAR float signal arrives at the input of the equipment, the recorded digital amplitude values can be small throughout the $24 \mathrm{~s}$ of the signal (48 amplitude samples) if the phase of the signal happens to be nearly out of phase with the local oscillator. We would expect, however, that the relative phase of the input signal and the local oscillator would be random for a series of float signals $6 \mathrm{~h}$ apart, and therefore an average over a series of float signals would be statistically less dependent on the phase of the input signal. Accordingly, the digital tape recordings were processed as follows:

A 48-sample running average of the $\frac{1}{2}-\mathrm{s}$ digital tape samples was computed and its square was plotted as a time series. This plot was visually examined for SOFAR float signals. Since the SOFAR float signals arrived at prescribed 6 -h intervals, it was possible to distinguish the float signal pulses in this chart recording from noise pulses. Occasionally, $(\sim 10 \%)$ the received SOFAR float pulse was about the same as that of noise pulses in the immediate vicinity of the expected ar- rival time. One amplitude value was chosen for each SOFAR float pulse identified every $6 \mathrm{~h}$, and a running average of nine of these pulses ( $2 \frac{1}{4}$-day average) was computed. The resulting time series are plotted for the three SOFAR floats in Fig. 1. Interruptions in the data of Fig. 1 (which became serious after 1 October) are indicated by dashed lines. No data were plotted unless nine consecutive pulses of a float signal could be measured.

There are three striking features of these time series: First, in the period from March through most of July, the amplitude levels on all floats are relatively low. Notice that from floats 1 and 4 the average peak amplitude level during this period is only a few decibels apart and the fluctuation range in decibels is smaller than in later periods. Second, there is an abrupt and large rise in amplitude level, 12-18 dB, on all floats toward the end of July and the higher levels persist for months. Third, all float signals reach levels in January that approximate levels received in the March to July period.

The sound transmission path of both floats 1 and 4 were on approximately the same bearing to Bermuda on 24 July, the time of the peaks in signal amplitude. If some propagation anomaly were between these floats and Bermuda, it would affect both float signals simultaneously on the date. Unfortunately, there is some uncertainty in the location of SOFAR float 2 (top record). It was caught up in the Gulf Stream on 20 February at approximately $34.2{ }^{\circ} \mathrm{N}, 74.9^{\circ} \mathrm{W}$ just southeast of Cape Hatteras. On $27 \mathrm{March}$, it was at approximately $37.3^{\circ} \mathrm{N}, 71.5^{\circ} \mathrm{W}$ after which it was not tracked because of loss of signal on one of two SOFAR receiving hydrophones. March 27 is about the date when acoustic mea-

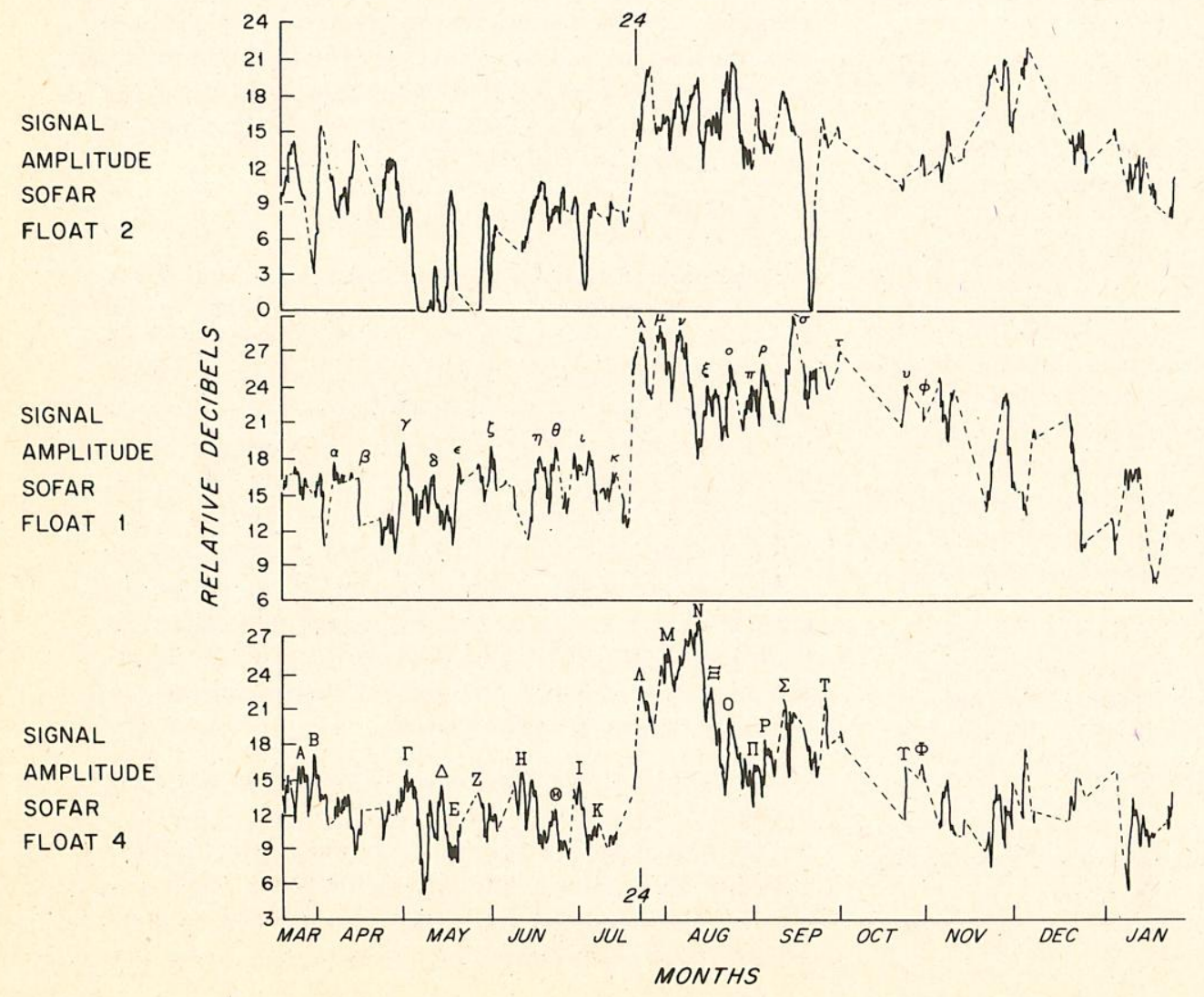

FIG. 1. Acoustic signal levels from SOFAR floats southeast of the Gulf Stream during 1975. The signal from each float was a $270-\mathrm{Hz}$ tone, $24 \mathrm{~s}$ long, emitted every $6 \mathrm{~h}$. A running average of only those data composed of nine consecutive pulses from each float are represented by the solid lines. An arbitrary reference level of $30 \mathrm{~dB}$ was taken for the received signal from float 1 on 15 Sept. 1975. Dashed lines indicate recording difficulties or poor signal reception because of noise. 
surements began in 1975 (Fig. 1). We note that the fluctuation in received level for float 2 during the period March to July is considerably larger than for the other two SOFAR floats and the average level is lower. Moreover, the peak amplitude level of SOFAR float 2 in late July does not reach as high as the amplitude levels of the other two floats. These observations are consistent with the view that float 2 is at a greater range from Bermuda. The abrupt rise and peak amplitude from SOFAR float 2 occurs four days after that of the amplitude peak level from floats 1 and 4 on 24 July as indicated by the pair of vertical lines in the record of float 2 in Fig. 1. All float signals were recorded on the same magnetic tape and routine calibrations of the receiving amplifier throughout the year showed that the gain remained constant. Consequently, the rise in signal level of all float signals toward the end of July in Fig. 1 is a sound transmission phenomena.

After study of both environmental and acoustical data for floats 1 and 4 , whose positions were known, a set of four independent studies was made of all the sketchy information concerning the positions of float 2 . The results indicated that this float was probably about twice the distance away from the receiving hydrophone on or about 24 July as float 1 and also it was in the vicinity of the bearing of the floats 1 and 4 (see Appendix A). This near coincidence of the bearing of float 2 from the receiver with those of floats 1 and 4 supports the hypothesis that an acoustic anomaly along the transmission path is responsible for the signal level rise late in July on all floats in Fig. 1. It is interesting that although floats 1 and 2 are at nearly at the same depth, the peak signal levels for float 2 are approximately $6 \mathrm{~dB}$ below those for float 1 in late July. This result should be expected if float 2 were about twice as far away from the hydrophone as float 1 .

\section{CORRELATION OF ACOUSTIC AND OCEANOGRAPHIC MOVEMENTS}

The subsequent discussion of the float signals in Fig. 1 will be restricted to SOFAR floats 1 and 4 only, since only their locations were reliably tracked acoustically during 1975 . The acoustically determined tracks of SOFAR floats 1 and 4 are shown in Fig. 2 for the period March to late October 1975. The black dots and small open circles along the tracks are 5 days apart. The float locations on July 24th are marked with a large open circle. Although they are at different ranges on that date, their bearing to Bermuda is approximately the same as shown by the straight line connecting them to Bermuda. The looping path of float 4 occurs because that float was trapped for several months in an intense Gulf Stream eddy (identified as Eddy 2) that moved slowly southwesterly at an average speed of about $4 \mathrm{~km}$ per day. It can be shown by plotting the location of SOFAR float 4 relative to the loca-

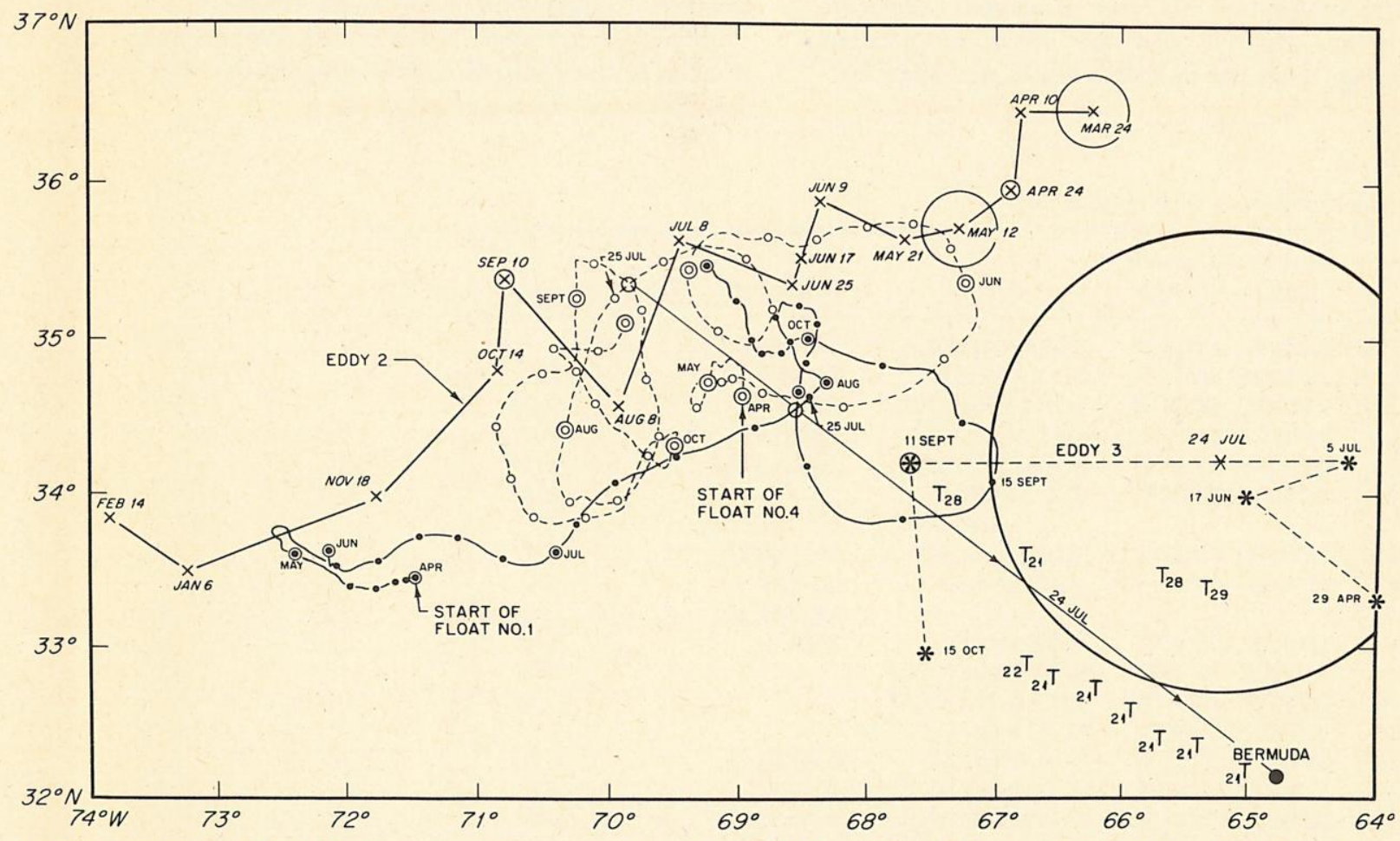

FIG. 2. Positions of SOFAR floats 1 and 4, and positions for Eddy 2 and Eddy 3 during 1975. The track of float 1 is the solid curve with solid dots marking 5-day intervals. Float 4's track is the dashed curve with corresponding open circles. The beginning of each month is designated by an additional small circle about the float position. Both float positions on 24 July are designated by larger open circles and they are joined by a straight line toward the receiver near Bermuda. Crosses with dates mark the measured locations of the centers of Eddy 2 and an asterisk with data designates known centers of Eddy 3 . Radii of uncertainty $\geqslant 10 \mathrm{~km}$ are given for Eddy 2 positions. Refer to Tables I and II for eddy position information. A large circle representing Eddy 3 centered on an estimated position, $X$, for 24 July is used to interpret data in this and Fig. 1 . BT-temperature profile positions in July are designated by $T$ with a number indicting the day. These represent all data between $35^{\circ}-32^{\circ} \mathrm{N} ; 68^{\circ}-65^{\circ} \mathrm{W}$ for the period 10 July -6 August. 
tion of Eddy 2, that the float was caught by Eddy 2 in May and then circled the center of the eddy at about a $40-\mathrm{km}$ radius through the month of October ( $\mathrm{R}$. Cheney, 1977, Fig. 6). ${ }^{6}$

The positions of the center of Eddy 2 are indicated by crosses in Fig. 2. The positions were determined by several ocean BT-temperature and salinity-temperature-depth, STD, surveys from ships, BT-temperature surveys from aircraft, and a few positions from satellite observations (see Table I). The date of each known position is indicated close to each cross. The straight lines drawn between the positions of Eddy 2 may, but do not necessarily, indicate the path of the eddy. Circles around some eddy positions indicate the uncertainty in the position of the center of the eddy. The two large uncertainty circles were associated with a specific satellite.

Float 1 moved northeasterly from mid-May to August and then meandered in a loop that brought it much closer to Bermuda on 15 September. The known positions of the center of another Gulf Stream eddy, Eddy 3, are indicated by an asterisk. The data supporting the positions of Eddy 3 will be presented in a later section. Dashed lines connecting these positions may, but do not necessarily, indicate the path of Eddy 3. It is clear from Fig. 2 that float 1 encircled Eddy 3 during September. After this, float 1 moved further away bringing it into the vicinity of its earlier positions. The largest peak amplitude level of the signal from float 1 occurs on 15 September, the data of closest approach to Bermuda (see Fig. 1). However, we do not attribute this very large increase in amplitude to a change in range only.
In Fig. 2 there are a number of positions marked by the cross of a $T$. These $T$ 's represent XBT-temperature profiles with the day of the measurement in July at their lower right. These temperature data, which were supplied by Paul Stevens of Fleet Numerical Weather Central, FNWC, were all that were available in the period $10 \mathrm{July}-6$ August for the area $35^{\circ}-32^{\circ} \mathrm{N}$, $68^{\circ}-65^{\circ} \mathrm{W}$. This period straddles the time of the large signal level increase in Fig. 1 and the measurements were located in the region between the SOFAR floats and the hydrophone near Bermuda.

Analysis of these data show that Eddy 3 was located in the region of the two BT positions $\left(65^{\circ}-66^{\circ} \mathrm{W}\right.$ and $33^{\circ}-34^{\circ} \mathrm{N}$ ) on the 28th and 29th of July but that all of the other BT's were outside the radius of influence of Eddy 3 for the dates indicated. The oceanographic observations show that Eddy 3 was a very large eddy. In the study of both acoustic and oceanographic data a boundary shown as a circle in Fig. 2 that encloses much of Eddy 3 was chosen to be tangent to the sound transmission path from the two floats on 24 July assuming the eddy moved uniformly from the 5 July to 11 September eddy positions. Accordingly, it is plausible that Eddy 3 was the cause of the large signal level increase on that date. The circular boundary shown in Fig. 2 may be considered as defining an effective acoustic radius for this eddy as a working hypothesis, and details of this interpretation of the data will be set forth in subsequent discussion. We first present a ray theoretic discussion of the sound transmission, follow this with description of the environmental data, and then give the analysis and interpretation of both the acoustic and oceanographic data.

TABLE I. Observations of Eddy 2 (ring D).

\begin{tabular}{|c|c|c|c|c|}
\hline Date & $\begin{array}{l}\text { Position of center } \\
\text { (Lat.) (Long.) }\end{array}$ & Source & Technique & Mean Eddy speed $(\mathrm{km} /$ day) \\
\hline 24 March 75 & $36^{\circ} 30^{\prime} \mathrm{N}, 66^{\circ} 15^{\prime} \mathrm{W}$ & GOES Satellite ${ }^{a}$ & Infrared & $\cdots$ \\
\hline 10 April 75 & $36^{\circ} 30^{\prime} \mathrm{N}, 66^{\circ} 45^{\prime} \mathrm{W}$ & NOO Aircraft ${ }^{\mathrm{a}}$ & 14 AXBT's & 2.6 \\
\hline 24 April 75 & $36^{\circ} 00^{\prime} \mathrm{N}, 66^{\circ} 50^{\prime} \mathrm{W}$ & NOAA-4 Satellite ${ }^{a}$ & Infrared & 4.00 \\
\hline 12 May 75 & $35^{\circ} 45^{\prime} \mathrm{N}, 67^{\circ} 15^{\prime} \mathrm{W}$ & GOES Satellite ${ }^{\mathrm{a}}$ & Infrared & 2.6 \\
\hline 21 May 75 & $35^{\circ} 40^{\prime} \mathrm{N}, 67^{\circ} 40^{\prime} \mathrm{W}$ & NOO Aircraft ${ }^{\mathrm{a}}$ & 10 AXBT's & 4.30 \\
\hline 9 June 75 & $35^{\circ} 55^{\prime} \mathrm{N}, 68^{\circ} 20^{\prime} \mathrm{W}$ & $\begin{array}{c}\mathrm{R} / \mathrm{V} \text { Trident } \\
168^{\mathrm{b}}\end{array}$ & & 3.5 \\
\hline 17 June 75 & $35^{\circ} 30^{\prime} \mathrm{N}, 68^{\circ} 30^{\prime} \mathrm{W}$ & NOO Aircraft ${ }^{a}$ & 10 AXBT's & 6.1 \\
\hline 25 June 25 & $35^{\circ} 22^{\prime} \mathrm{N}, 68^{\circ} 35^{\prime} \mathrm{W}$ & USNS Lynch ${ }^{\mathrm{a}}$ & $\begin{array}{l}60 \text { XBT's } \\
10 \text { STD's }\end{array}$ & 2.1 \\
\hline 8 July 75 & $35^{\circ} 35^{\prime} \mathrm{N}, 69^{\circ} 25^{\prime} \mathrm{W}$ & USNS Lynch $^{\mathrm{a}}$ & XBT's & 6.1 \\
\hline 8 Aug. 75 & $34^{\circ} 35^{\prime} \mathrm{N}, 69^{\circ} 55^{\prime} \mathrm{W}$ & $\mathrm{R} / \mathrm{V}$ Chain $\# 125^{\mathrm{c}}$ & & 3.9 \\
\hline 10 Sept. 75 & $35^{\circ} 23^{\prime} \mathrm{N}, 70^{\circ} 47^{\prime} \mathrm{W}$ & $\mathrm{R} / \mathrm{V}$ Chain $\# 127^{\mathrm{d}}$ & & 3.60 \\
\hline 14 Oct. 75 & $35^{\circ} 00^{\prime} \mathrm{N}, 71^{\circ} 00^{\prime} \mathrm{W}$ & R/V Eastwood & & \\
\hline 14 Oct. 75 & $34^{\circ} 50^{\prime} \mathrm{N}, 70^{\circ} 50^{\prime} \mathrm{W}$ & NOO Aircraft ${ }^{\mathrm{a}}$ & 8 AXBT's & 1.8 \\
\hline 18 Nov. 75 & $34^{\circ} 00^{\prime} \mathrm{N}, 71^{\circ} 45^{\prime} \mathrm{W}$ & $\mathrm{R} / \mathrm{V}$ Knorr $\# 53^{\mathrm{c}}$ & 70 XBT's & 3.6 \\
\hline 6 Jan. 76 & $33^{\circ} 30^{\prime} \mathrm{N}, 73^{\circ} 15^{\prime} \mathrm{W}$ & NOAA-4 Satellite ${ }^{a}$ & Infrared & 3.0 \\
\hline 14 Feb. 76 & $33^{\circ} 50^{\prime} \mathrm{N}, 73^{\circ} 50^{\prime} \mathrm{W}$ & NOO Aircraft ${ }^{\mathrm{a}}$ & AXBT's & 1.7 \\
\hline & & \multicolumn{2}{|c|}{$\begin{array}{l}\text { Grand mean } \\
\sigma=\text { st. dev. }\end{array}$} & $\begin{array}{l}3.5 \\
1.3\end{array}$ \\
\hline
\end{tabular}

\footnotetext{
${ }^{a}$ R. E. Cheney, NAVOCEANO.

${ }^{\mathrm{b}}$ P. Richardson, W.H.O.I.

${ }^{c}$ P. Wiebe, W.H.O.I.

${ }^{\mathrm{d}}$ R. Porter, R. Spindel, W.H.O.I. Analysis (Jessup, Beckerle).

${ }^{\mathrm{e}}$ N. Hogg, W.H.O.I.
} 


\section{CAUSTIC SURFACES NEAR THE SOUND CHANNEL AXIS}

Much of the short-term fluctuations of the signal levels observed in Fig. 1 can be explained using ray computations for the positions of caustics near the sound channel axis formed by adjacent rays from the source, Kinney and Pierce. ${ }^{7}$ Figure 3 is a ray diagram obtained using an extension of the Hirsch-Carter $(1965)^{8}$ sound speed profile approximation (dotted points) to an actual sound speed profile (solid curve) obtained from STD measurements for the area outside of the region of Eddy 3 in 1975. The profile has three parameters, $\alpha, \beta$, and $C_{0}$. The form of the Hirsch-Carter function is:

$$
C^{2}(z)=C_{0}^{2}\left(1-(\alpha z)^{\beta}\right)^{-1},
$$

where $C$ is the sound speed, and $C_{0}$ its value at the axis, $z=0$.

Different parameter values of $\alpha$ and $\beta$ were used above and below the sound channel axis; the values above were $\alpha=0.33590 \mathrm{~km}^{-1}, \beta=2.05506, C_{0}=1492.75$ $\mathrm{m} / \mathrm{s}$ and values below the axis were $\alpha=0.33590 \mathrm{~km}^{-1}$, $\beta=1.25931$. The two profiles are joined at the axis where they are continuous and have a continuous gradient. The fit shown by the dots on the profile is excellent except for depths that are shallower than $500 \mathrm{~m}$. Joining the sound speed profiles in this manner permits the use of the closed form of the mathematical expression for the theoretical ray travel times and range solution of Hirsch and Carter for symmetrical profiles to the more asymmetrical oceanic sound speed profile. The technique is described by L. Baxter $(1978)^{9}$ and includes description of sound speed profiles obtained within and at the boundary of Eddy 3 .

The SOFAR float transmitters were near but below the sound channel axis, and the receiver was a few hundred meters above the axis; consequently, only portions of caustic zones are illustrated in Fig. 3 with dashed lines, labeled $B_{1}, B_{2}, \ldots$ and $C_{1}, C_{2}, \ldots$. The ray diagram was kept particularly simple for the purpose of comparison with observations. A much more complete ray diagram for a typical deep ocean sound speed profile that illustrates the region of caustics in more detail may be found in Urick's book. ${ }^{10}$ A recent paper by Baer ${ }^{11}$ presents theoretical intensity at caustics for sound propagation from a source located at the center of a typical ocean eddy using the parabolic approximation to the wave equation.

Figure 4 shows a plot of the peak signal level from floats 4 and 1 as function of range from the hydrophone where range is expressed in terms of the order number of $B_{N}$ and $C_{N}$ caustics as calculated from Fig. 3. Several of the peaks occurring prior to 24 July, which are lower in level, i.e., $B, \Delta, \Gamma$, and $I$, indicate approximately a $6-\mathrm{dB}$ decrease doubling the distance, and dashed vertical lines indicate they occur at the ranges calculated for caustic peaks to occur when no eddy is located between the floats and the hydrophone. Only $\theta$ and $H$, which occurred in June from float 4, are shown to lie between caustic locations, and we will show later that the sound in their case did pass through Eddy 3. The inverse square of the distance fall in peak signal level is expected approximately because the peak caustic signals result from sound propagating along adjacent rays that intersect to form a caustic. ${ }^{7}$ However, the theory of caustics given by Brekhovskhih ${ }^{12}$ leads to a $5-\mathrm{dB}$ decrease in intensity when the distance is doubled and this trend clearly fits long segments of the observed averaged peak level, although these segments of data appear at different levels from other long segments. The fact that the data appears able to distin-

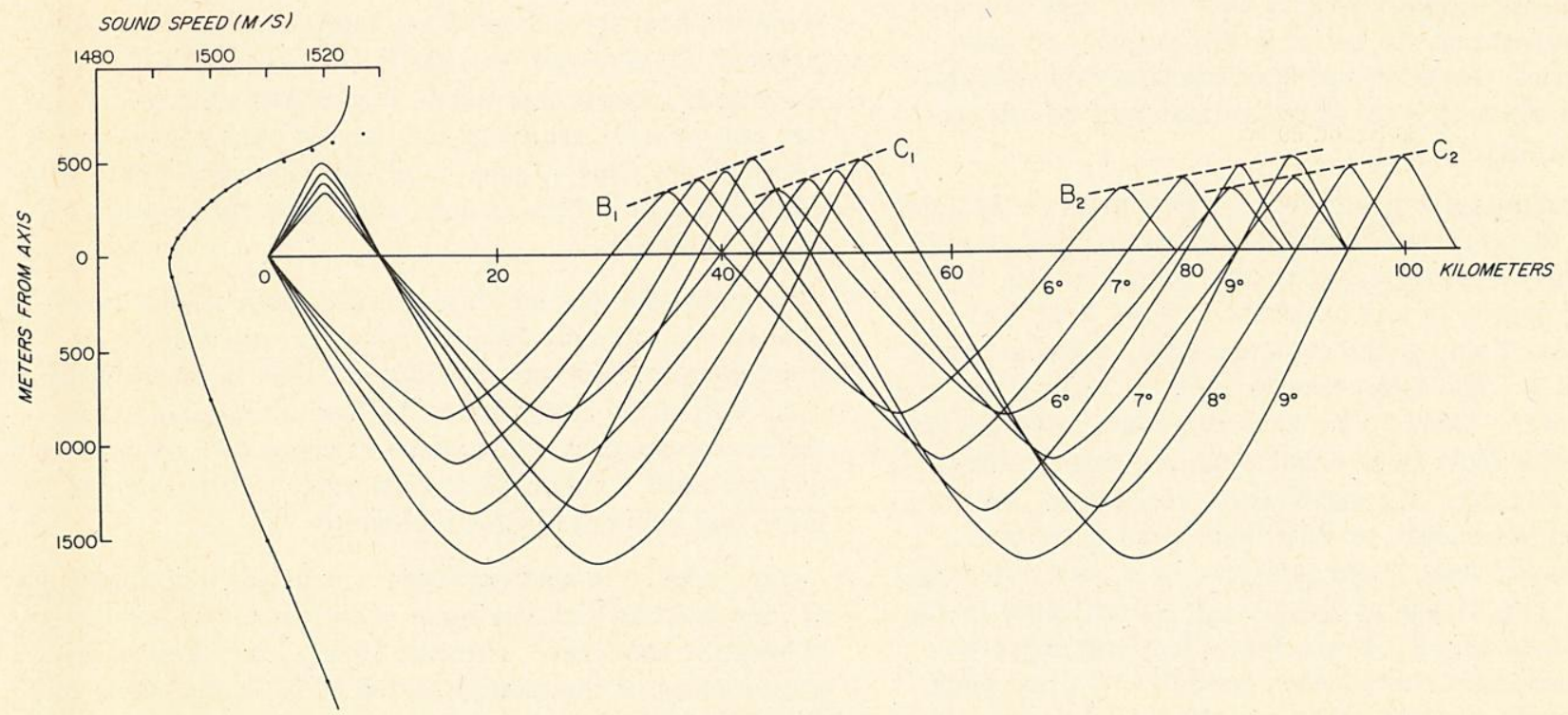

FIG. 3. A ray diagram for rays $6^{\circ}, 7^{\circ}, 8^{\circ}$, and $9^{\circ}$ from the horizontal for both up and down going rays for the source located at $X=0 \mathrm{~km}$ and at sound channel axis depth $Z=0$. The sound speed profile (solid curve) is valid for the area when no eddies are present. The rays were calculated using a Hirsch-Carter function approximation (solid dots) to the sound speed profile (solid curve). Caustic surfaces formed by the rays above the axis are shown by dashed lines labeled $B_{1}, C_{1}, B_{2}, C_{2}$, etc. where the subscripts indicate the order of the caustics. The hydrophone depth was a few hundred meters above the axis and, therefore, would intercept the region of the caustic surfaces at regular range intervals. 


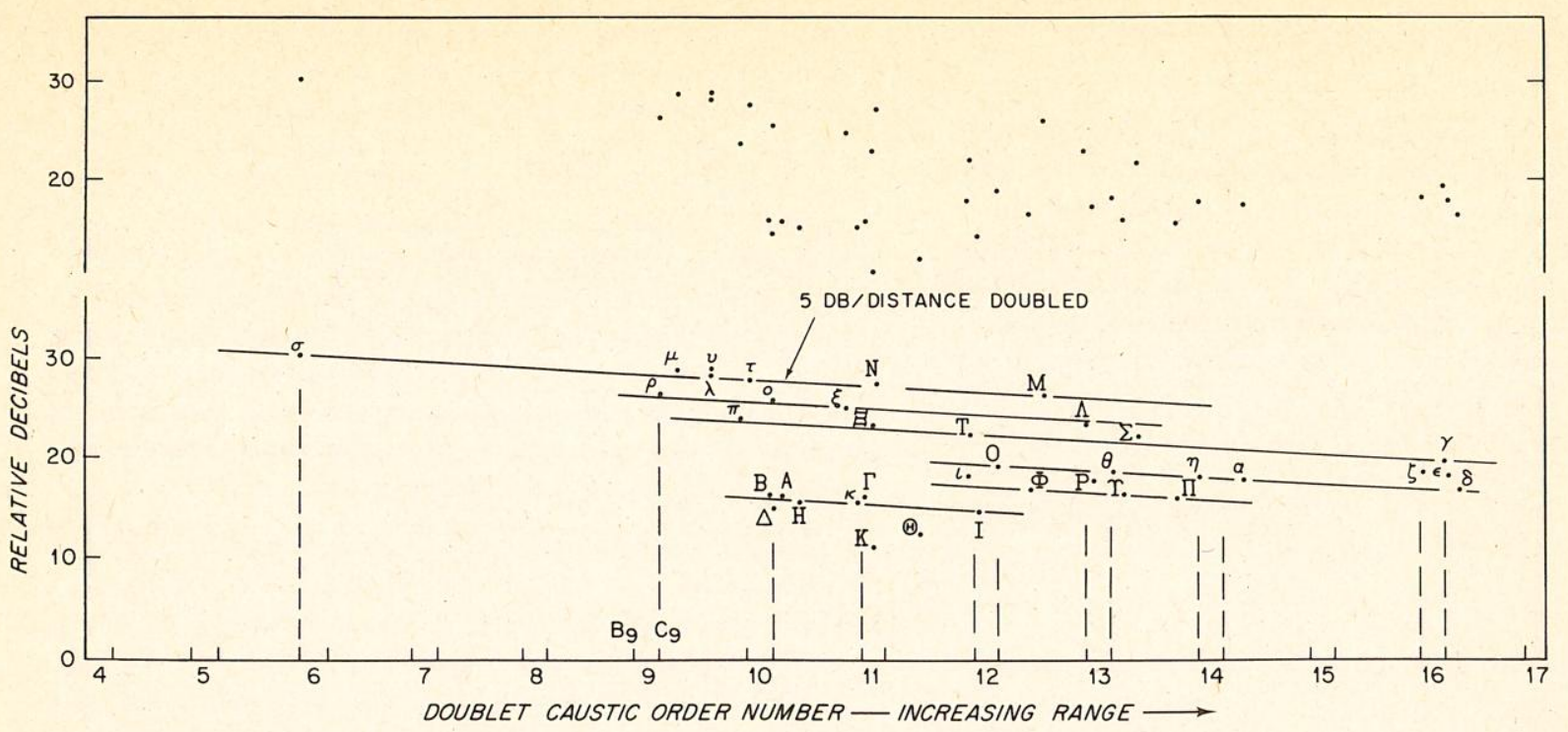

FIG. 4. Peak levels as a function of range given in terms of the order number of caustic positions obtained for the case of noeddy between SOF AR floats and the hydrophone from the ray diagram in Fig. 3 . Greek letters correspond to signal peaks designated in Fig. 1. All points have been positioned above figure proper without labels or trend lines to allow sighting along edge of paper to establish conviction of trend without bias.

gui sh between a 6 - and a 5-dB/distance doubled slope is considered remarkable, and will be discussed further in the section on theoretical considerations. The Greek letters designating the peaks in Fig. 4 that are needed to cross reference with Fig. 1 make it difficult to clearly see that the scatter of the data points do confirm the possible construction of several straight lines of $5 \mathrm{~dB}$ per distance doubled through them. This slope is significantly different from a steeper general trend line one might draw through all points but such a general trend line would lack physical significance. All of the points were plotted above without any lines through them or identifying letters in order to allow the reader to sight along various directions without bias to convince himself that the set of $5-\mathrm{dB} /$ distance doubled slopes exist. An explanation of this discrete variability in the average level of trend lines will be offered in a later section.

The transmission peaks from float 1 prior to 24 July occur at the calculated locations of the narrow caustic zone using the sound speed profile shown in Fig. 3. They are higher in level than those from float 4 although float 1 was at the greater range, such as peaks $\eta, \theta$, and $\alpha$. The difference in level of $5 \mathrm{~dB}$ will be explained later. Eddy 3 may have had some influence on signal peaks from float 1 that were recorded prior to the dramatic rise in a signal level on 24 July, but its effect was not enough to shift their focal positions. For instance, float 1 , for peaks $\gamma, \delta, \epsilon$, and $\delta$ during May (see Fig. 1) was at large range as indicated by the float track in Fig. 2. From Fig. 4 the first three positions were near the location of caustic $C_{16}$ and peak $\zeta$ was near $B_{16}$. A straight line to the receiver for the sound path from the track positions of float 1 during May in Fig. 2 would intercept a small portion of the southern edge of the effective acoustic radius for Eddy 3 if this circle were centered at the position given for Eddy 3 on April 29. Besides some influence on these signal levels from Eddy 3 in May for float 1, there may also be an effect that results from the floats proximity to the eastern side of the Gulf Stream where there is a rise in the main thermocline (see Fig. 2).

The highest peak levels observed for the period from 24 July, i.e., $\lambda, \mu, \nu, N$, and $M$ are shown in the figure as decreasing inversely slightly less than with the square of the range; however, except for peak $N$ they fall between the calculated ranges for caustic locations obtained for the case when no eddy is present between the floats and the hydrophone. Peak $\mu$ is separated about $10 \mathrm{~km}$ from peaks $\nu$ and $\lambda$, and this indicates that both $B_{9}$ and $C_{9}$ were shifted a considerable distance from the position expected for them when no eddy is present. Since peak $M$ was shifted half-way between two calculated caustic positions, it is reasonable to consider that peak $N$, which is the largest peak signal received from float 4 , may have been shifted a whole ray cycle distance. This is consistent with its location at order 11 in Fig. 4.

We conclude that not only was the large signal level change commencing 24 July caused by changes in the transmission medium, but that changes in the medium also shifted the positions of the narrow caustic zones. Estimates suggest an increase of about $0.75 \mathrm{~dB}$ per $\mathrm{km}$ of focal shift. Theoretical arguments will be offered later that support these conclusions.

Our concern is whether Eddy 3 could be unambiguously identified as causing some of the principal acoustic anomalies observed. Because floats 1 and 4 were approximately on the same bearing to the hydrophone on 24 July when the large rise in signal level occurred, we considered the hypothesis that the large acoustic amplitude rise and fluctuations occurring late in July and after could be attributed to the movement of Eddy 3 into the transmission path of the SOFAR floats. The possible effects of Eddy 2 on the signal reception from 
float 4 complicates establishing the hypothesis, but some signal levels from float 1 cannot be attributed to Eddy 2 because the eddy was located at a greater range than float 1 from the hydrophone. A study of all of the oceanographic data for evidence of the position of the eddies, in particular, Eddy 3 which is crucial to the interpretation of the acoustics is summarized in the next section. However, the reader may defer reading this section in order to concentrate first on acoustic effects.

\section{OCEANOGRAPHIC DATA}

The positions of the centers of the two main Eddies 2 and 3 shown in Fig. 2 have been plotted from data collected from several sources. Lists are given in Table I and Table II and the average speeds of the eddies between successive positions are also tabulated there. The track of Eddy 2 in 1975 shown in Fig. 2 is the most complete and it was continued through 1976 until Eddy 2 rejoined the Gulf Stream. Satellite infrared techniques for locating ocean eddies are particularly valuable when there are temperature contrasts greater than $\frac{1}{2}^{\circ} \mathrm{C}$. In July, at large distances from the Gulf Stream the temperature contrasts are not sufficient to detect eddies, and other methods are required. This is, in part, the reason for the relatively few fixes on the position of Eddy 3.

Figures 5 and 6 (courtesy of R. Cheney ${ }^{13}$ ) show the positions of Eddy 2 and 3 for 5 July and 15 October. Temperature cross sections for both Eddy 2 and Eddy 3 obtained during the cruise shown in Fig. 5 are presented in Fig. 7 and Fig. 8 (courtesy of R. Cheney). It is clear from these pictures that Eddy 3 is very large and different shape from Eddy 2. Figures 5 and 6 demonstrate that Eddy 3 moved southwesterly between the floats and the hydrophone during the SOFAR transmission period. Besides the aircraft BT observations by $\mathrm{R}$. Cheney indicated in Fig. 6, and independent cruise of the $R / V$ Eastward by N. Hogg et al. ${ }^{14}$ from Beaufort, North Carolina to Bermuda and return, obtained temperature and GEK measurements through both Eddy 2 and Eddy 3 about 15 October. The temperature cross section for Eddy 3 that was obtained indicated that the eddy, located near $33^{\circ} \mathrm{N} 68^{\circ} \mathrm{W}$, was very large in size in comparison with Eddy 2, and this insured its identification as the same eddy, called Eddy 3, in Fig. 5.

The evidence that Eddy 3 moved to the position shown in Fig. 2 for 11 September comes from analysis of XBT observations from $R / V C H A I N$ cruise 127. A portion of the cruise track is shown in Fig. 9 and the numbers along the ship's track are XBT numbers. The $15^{\circ}$ isotherms rose to a minimum depth of $430 \mathrm{~m}$ at BT \#3738 and to a depth of $500 \mathrm{~m}$ at BT \#18. The minimum depth to which isotherms rose along the track near BT \#37 and \#38 permits an estimate of the distance to the eddy center assuming that the temperature cross section in Fig. 11 for Eddy 3 can be used. The direction of the eddy center from the ship's track was deduced from the fact that the ship was set from its course direction by the counterclockwise circulation about the eddy center. Moreover, SOFAR float 1 moved along a large counterclockwise path around the September 11 position. The remaining XBT section to Bermuda confirmed that there was no large eddy between $67^{\circ} \mathrm{W}$, $33.5^{\circ} \mathrm{N}$ and Bermuda. These data support the identification that Eddy 3 moved from its 5 July position to the 11 September position and then southward to the 15 October position. The 10 September position for Eddy 2 shown in Fig. 2 was obtained from a similar study of XBT's, the set of the ship, and the movement of float 4 in Fig. 9.

Prior to 5 July, a position of Eddy 3 shown in Fig. 2 for 29 April was reported by McCartney et al. ${ }^{15}$ The position of Eddy 3 on 17 June which is southwest of the 5 July position was obtained by R. Cheney from aircraft XBT's on two days -17 and 19 June. The inter-

TABLE II. Observations of Eddy 3.

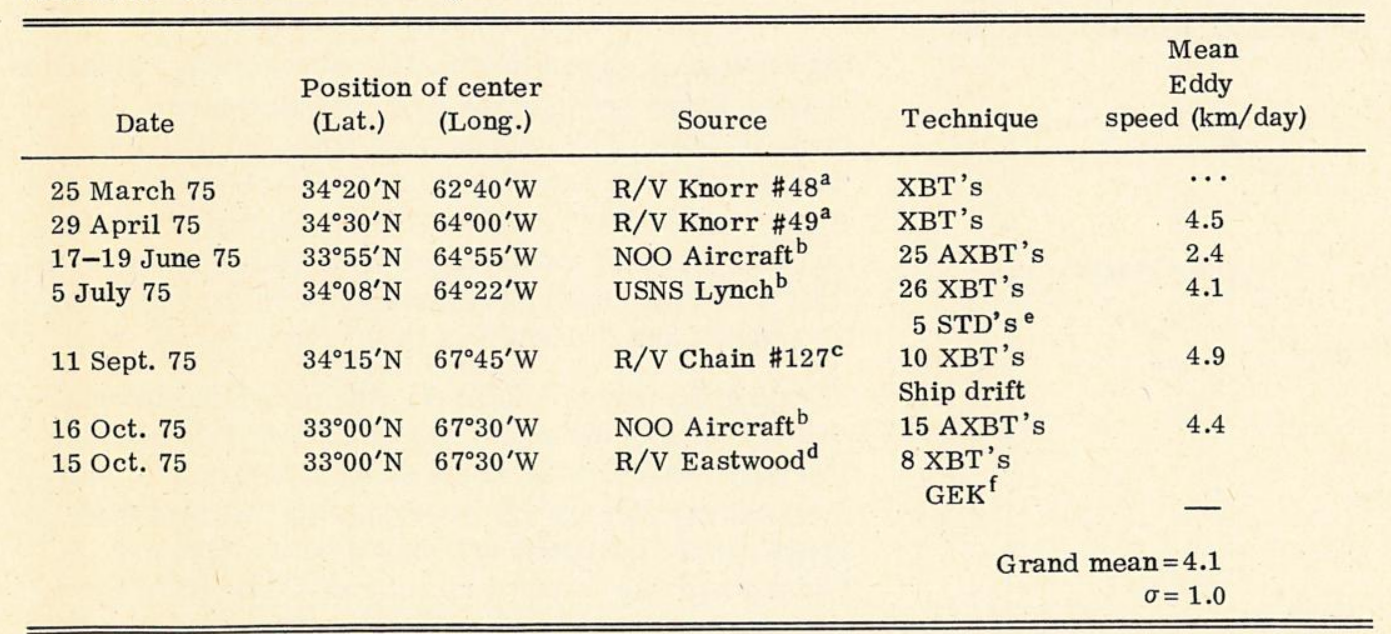

\footnotetext{
${ }^{a}$ M. McCartney, ${ }^{11}$ W. H. O.I.

${ }^{\mathrm{b}} \mathrm{R}$. E. Cheney, NAVOCEANO.

${ }^{c}$ R. Porter, R. Spindel, W.H.O.I. Analysis, A. Jessup, J. Beckerle.

${ }^{\mathrm{d}}$ N. Hogg, ${ }^{10}$ W.H.O.I.

${ }^{\mathrm{e}}$ STD is salinity, temperature, depth measuring instrument.

${ }^{f}$ Towed electromagnetic current speed instrument.
} 


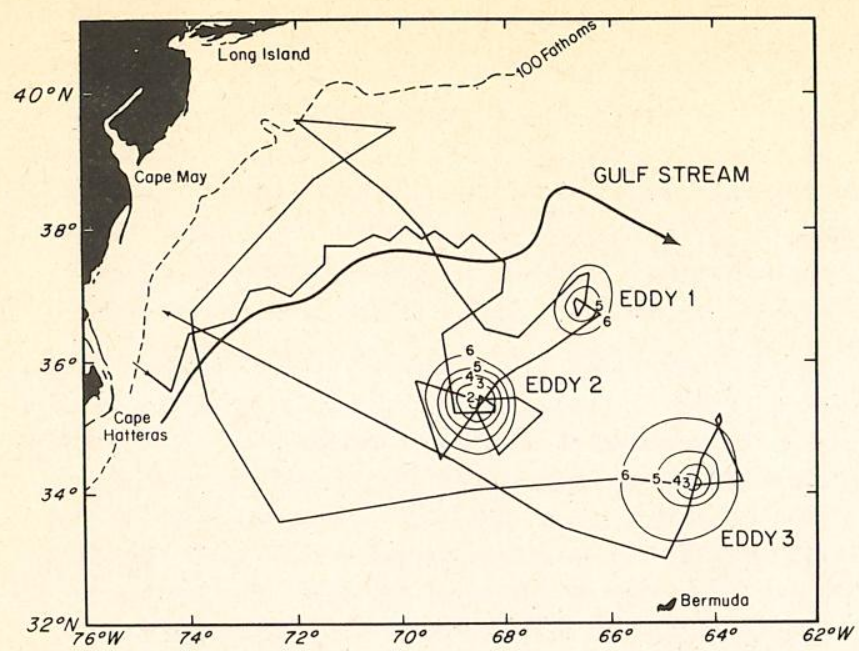

FIG. $5.15^{\circ} \mathrm{C}$ Isotherms with depths labeled in hundreds of meters indicate positions of Eddies 2 and 3. The track of the $\mathrm{R} / \mathrm{V}$ Lynch is for the period around 5 July 1975. See Tables I and II. The course of the Gulf Stream is also shown. Courtesy of R. E. Cheney, NAVOCEANO.

sections of isothermal surfaces with the $300-\mathrm{m}$ depth are shown for Eddy 3 and Eddy 2 in Fig. 10 (courtesy of R. Cheney). It is obvious again that Eddy 2 and Eddy 3 are very different in shape and extent as was pointed out in connection with Figs. 5 and 6.

Figure 11, which will be needed in later discussion, is a composite of the BT observations for Eddy 3 that shows more detail for the isotherms above $850 \mathrm{~m}$ than in Fig. 8. It was obtained from the BT sections along the tracks through Eddy 3 shown in Fig. 5 . There is evidence in Fig. 11 that Eddy 3 extends beyond $167 \mathrm{~km}$ $=90 \mathrm{NM}$ from the center. We used this value to represent an estimate of an effective acoustic outer boundary for Eddy 3 in Fig. 2 under the simplified assumption of straight line paths between known fixes of the eddy.

Comparing the distances from the center to the $17{ }^{\circ} \mathrm{C}$ and $18{ }^{\circ} \mathrm{C}$ curves in Eddy 3 in Fig. 10 with the corresponding distances for the depth of $300 \mathrm{~m}$ in Fig. 11 for 5 July, there is evidence for the long gradual skirt of

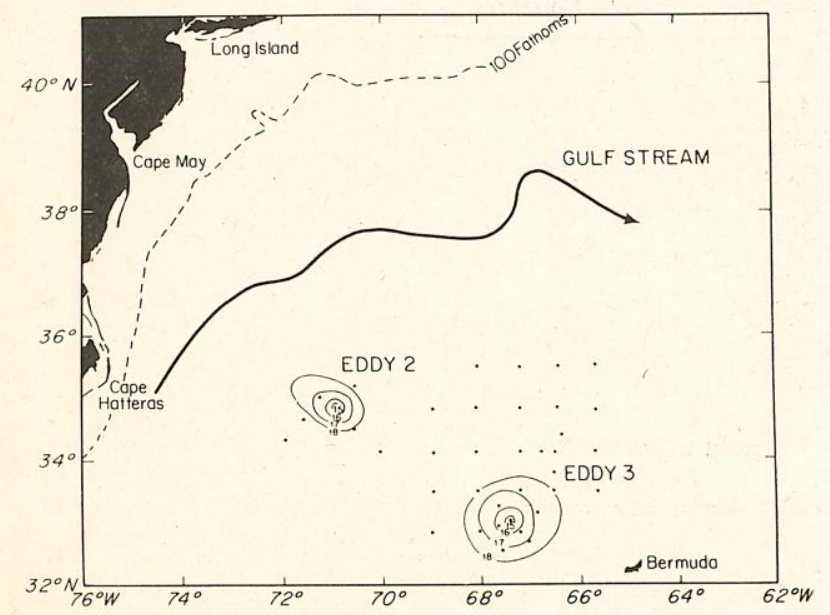

FIG. 6. Positions of isotherms in ${ }^{\circ} \mathrm{C}$ at depth of $300 \mathrm{~m}$ for Eddy 2 and Eddy 3 obtained from Airdrop XBT's (solid dots) for 15 October 1975 .

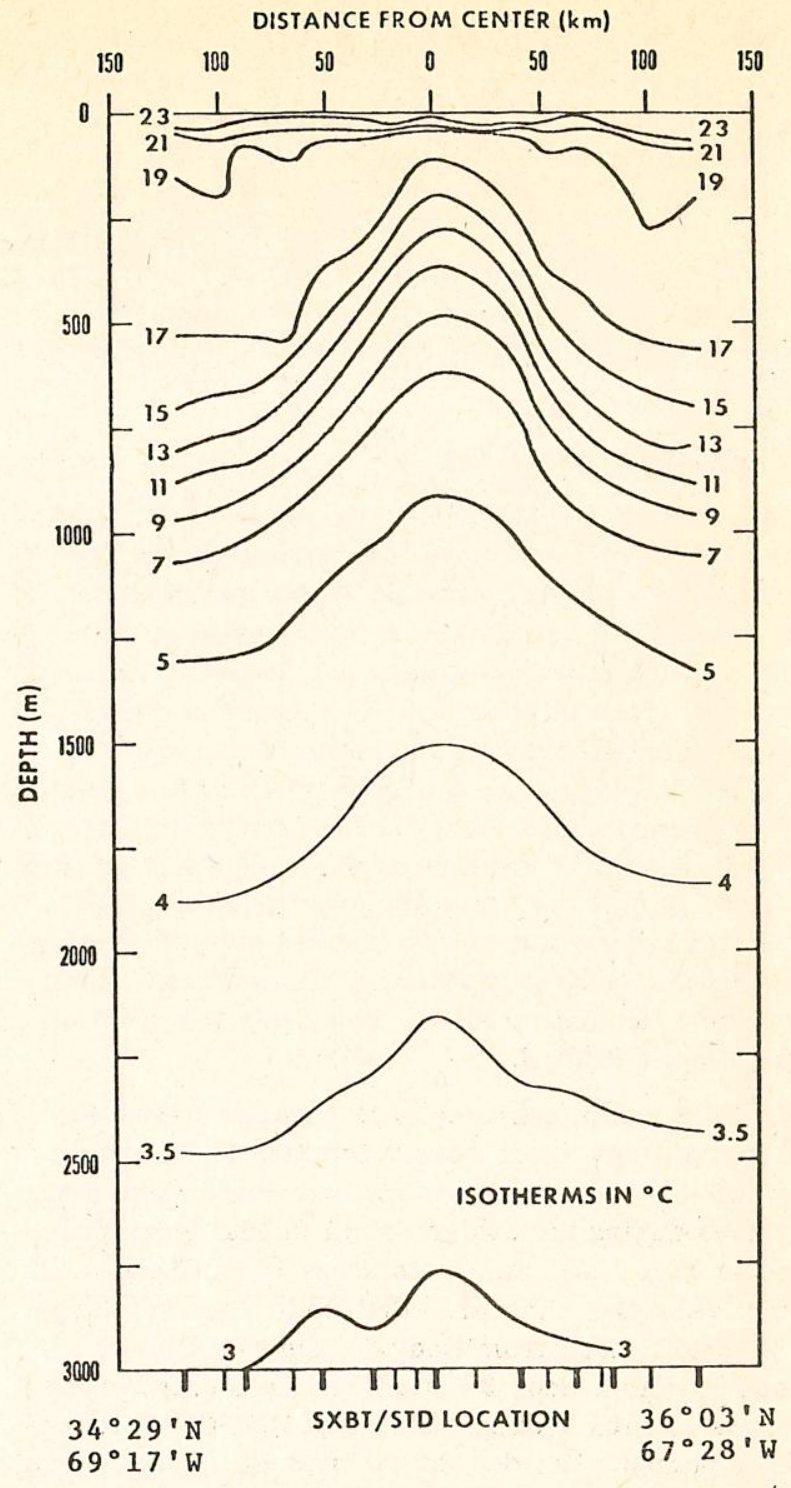

FIG. 7. Isotherm section through Eddy 2 for track of $\mathrm{R} / \mathrm{V}$ Lynch shown in Fig. 5 (see Table I). Courtesy of R. E. Cheney, NAVOCEANO.

the isotherms shown in Fig. 11. Accordingly, a portion of Eddy 3 was between the float 4 positions and Bermuda in June. This can be seen from the positions of. float 4 on 9 June and 17 June which were inserted in Fig. 12 within Eddy 2. One should, therefore, expect that Eddy 3 could modify the sound transmission from float 4 in June, such as, causing the shift of the caustic zones $\theta$ and $H$ described in the previous section.

During the period 5 July-11 September the information concerning the whereabouts of Eddy 3 is scarce. The only observations in the critical interval 10 July6 August are the few BT observations obtained from FNWC whose positions are shown with a $T$ in Fig. 2. The sea surface temperatures from these BT's were compared with expected values for the area between the floats and Bermuda for the month of July that were given in tabulations of all BT's from 1945-1975 as compiled by E. H. Schroeder and Phyllis Bailey of the Woods Hole Oceanographic Institution. This established the reasonableness of the BT's in Fig. 2 since sea sur- 


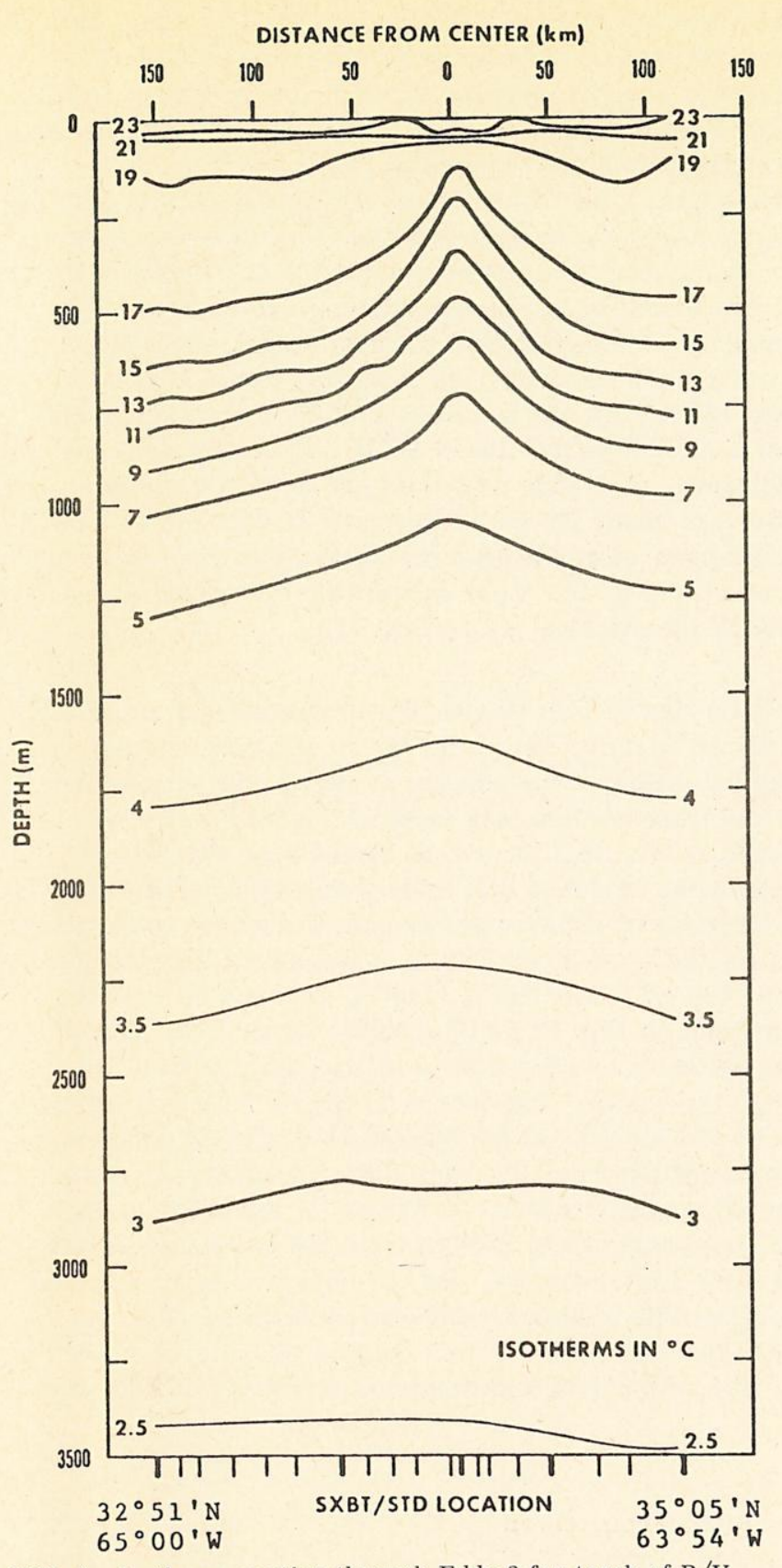

FIG. 8. Isotherm section through Eddy 3 for track of $\mathrm{R} / \mathrm{V}$ Lynch shown in Fig. 5 (see Table II). Courtesy of R. E. Cheney, NAVOCEANO.

face temperatures increase approximately $2{ }^{\circ} \mathrm{C}$ per month during spring and summer. Most of the BT's obtained on 21 July that were south of the circular boundary in Fig. 2, which approximately represents the lateral extent of Eddy 3, do not contain evidence of the influence of Eddy 3. The BT's located within the circle representing the effective acoustic radius of Eddy 3 for 24 July in Fig. 2 were definitely within the eddy on the day in July indicated for the BT. We will show this in the next section by comparing their temperature-depth relationship with the cross section of Eddy 3 in Fig. 11. The distances these BT's are from the eddy center is uncertain because of changes in its shape as it propagates. Table II shows that the mean speed of the eddy from 5 July-11 September was $4.9 \mathrm{~km} /$ day and this high speed suggests that it might have stayed close to

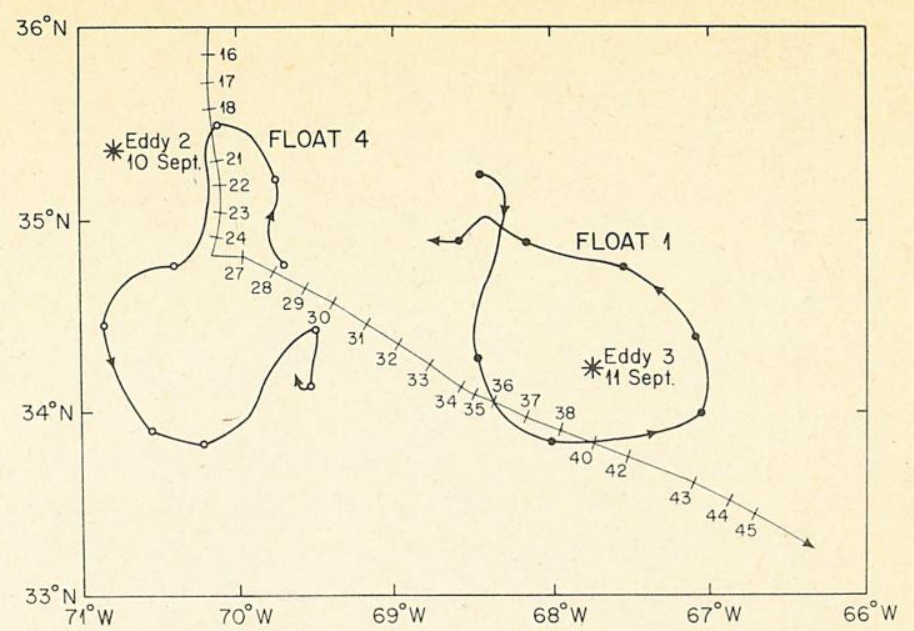

FIG. 9. Track of $\mathrm{R} / \mathrm{V}$ Chain Cruise 127 and portions of SOFAR float tracks in September as they relate to Eddy 2 and Eddy 3 .

the dashed straight line shown in Fig. 2. Nevertheless, much faster and more erratic movements for Eddy 3 are possibly compatible with the acoustic data.

These oceanographic observations will be used in the following section to set forth an interpretation of some of the acoustic signal fluctuations in Fig. 1 in terms of focusing by Eddy 3 .

Two severe storms traversed the region of the SOFAR floats. They were tropical storm Amy, dates 26 June to 4 July and hurricane Blanche, 23 July to 28 July. Both of these storm centers took paths between $33.5 \mathrm{~N}$ $73^{\circ} \mathrm{W}$ and $37^{\circ} \mathrm{N} 67.5^{\circ} \mathrm{W}$ which is over positions of Eddy 2 (see Fig. 2). It is well known that hurricanes can cause large scale upwelling in the ocean and for this reason the track of hurricane Blanche was examined to see if there was any chance that the upwelling might have produced the large rise in acoustic signals ob-

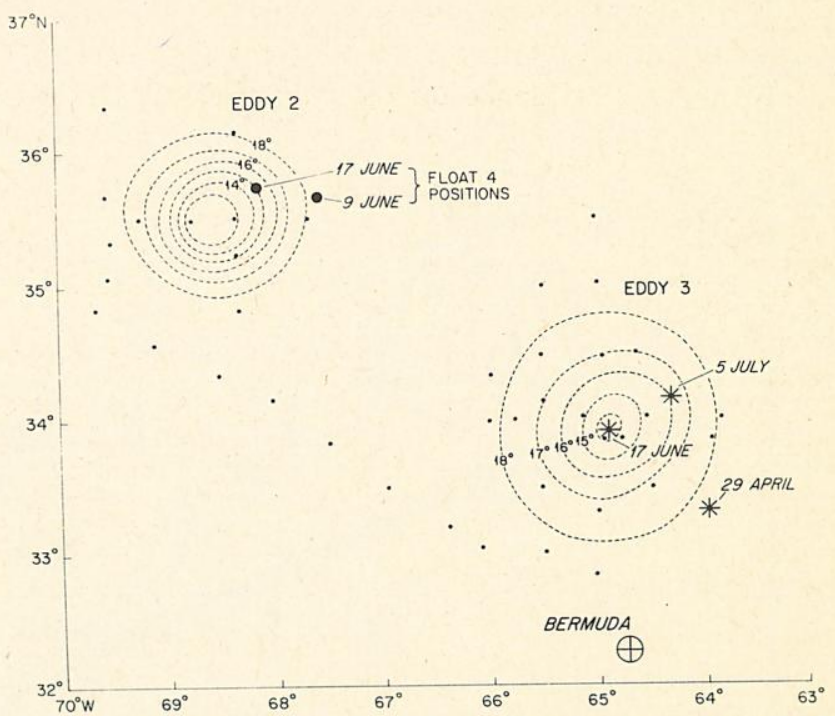

FIG. 10. Isotherms for 300-m depth of Eddy 2 and Eddy 3, 1719 June 1975 from Airdrop XBTS (solid dots). Two positions for SOF AR float 4 for 17 June and 9 June in Eddy 2 are shown in relation to Eddy 3 and receiver near Bermuda. Three positions of the center of Eddy 3 are shown by an asterisk. Courtesy R. E. Cheney, NAVOCEANO. 


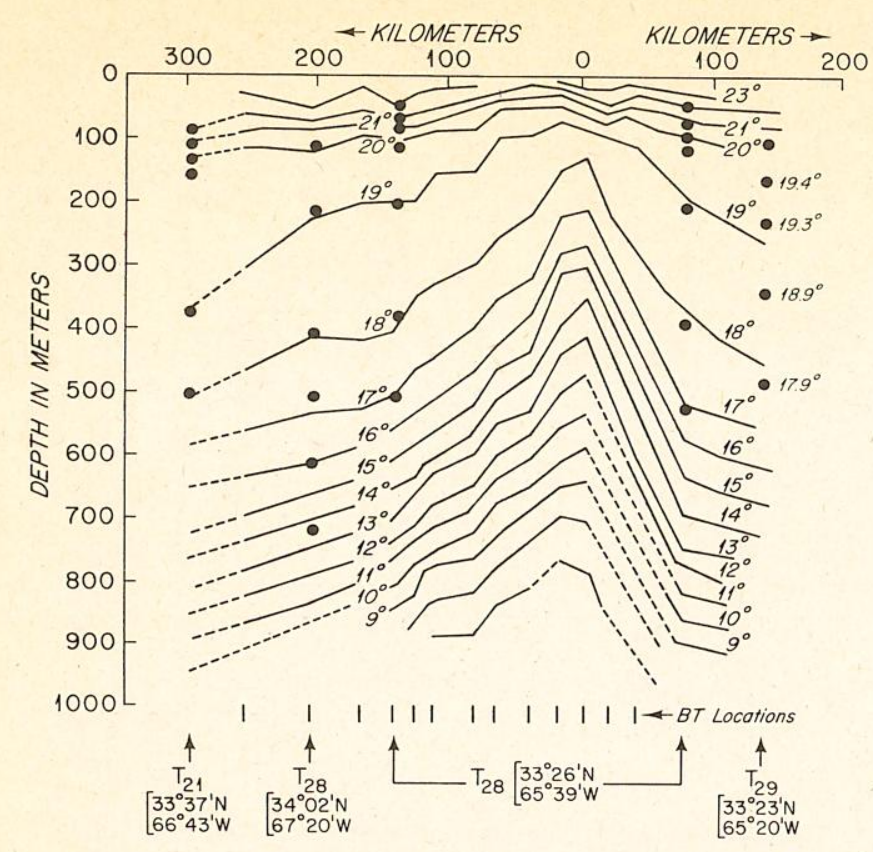

FIG. 11. Composite isotherm section for Eddy 3 with the BT locations from cruise of $\mathrm{R} / \mathrm{V}$ Lynch in July indicated by the row of bars at bottom of figure. BT locations from Fig. 2, designated by $T$, are also shown and their temperature-depth values (solid dots) are indicated for comparison with Eddy 3 isotherms.

served in Fig. 1. However, hurricane Blanche was located at about $24{ }^{\circ} \mathrm{N}, 70^{\circ} \mathrm{W}$ (east of the tip of Florida) at 7 a.m. EST on 24 July (P. J. Hebert ${ }^{16}$ ). Therefore it is not involved as a cause of the acoustical fluctuation observed on that date from the SOFAR floats.

\section{ACOUSTIC FLUCTUATIONS ATTRIBUTED TO FOCUSING BY EDDY 3}

The speed of eddy movement obtained from the positions shown in Fig. 2 and the number of days between them are tabulated in Table I and Table II. Using the assumption that the westward movement of Eddy 3 followed closely along the straight line path shown in Fig. 2 from 5 July to 11 September at a constant speed because it was high compared to the mean speed between fixes, one can estimate the position of the eddy on various dates in July and August. Some are shown in Fig. 12 and for each position there is a circular arc drawn to represent the hypothetical extent of the eddy anomaly. In keeping with the assumption about this circular arc, it is obvious from this figure that on 21 July the arc for the boundary of Eddy 3 (dashed circle) did not reach to the line of BT's that extend out from Bermuda. The eddy also does not influence the temperature at the BT on 21 July near $33.6^{\circ} \mathrm{N}$ and $66.7^{\circ} \mathrm{W}$. The temperatures at specific depths for this BT were plotted in Fig. 11. They only fit the Eddy 3 cross section at the extreme left of Fig. 11.

Referring to Fig. 12 and the estimated position of the Eddy on 24 July, the circle for an effective acoustic radius of Eddy 3 was chosen so that it just grazes the sound transmission path from the floats 1 and 4 because at this time the signal levels rose abruptly. Supporting evidence that Eddy 3 was approximately at the estimated position shown can be seen by noting its estimated position on 28 July a few days later and the fact that BT's labeled $T_{28}$ and $T_{29}$ between $65^{\circ}-66^{\circ} \mathrm{W}$ longitude in Fig. 12 would clearly indicate the rise of the isotherms within Eddy 3 at the range $80-130 \mathrm{~km}$ from the center. The fact that they do is shown in Fig. 11 by the location of the black dots of the BT temperatures and the solid lines for Eddy 3 isotherms. Also, the BT on 28 July between $67^{\circ}-68^{\circ} \mathrm{W}$ longitude in Fig. 12 is approximately $180 \mathrm{~km}$ from the estimated center of Eddy 3 for that date, and the observed temperatures confirm this (distance $\sim 200 \mathrm{~km}$ ) as shown in Fig. 11 . The correspondence at this point is considered good in view of position and shape uncertainties of Eddy 3 .

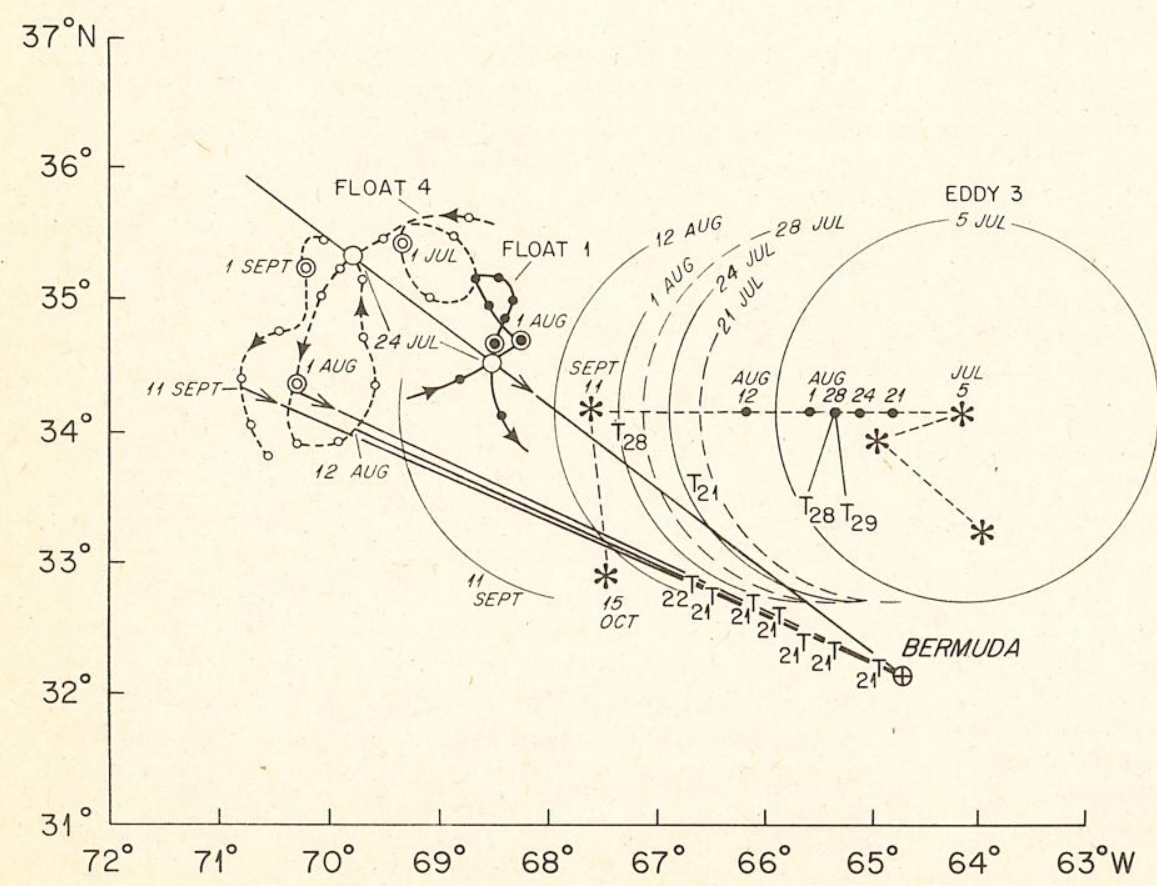

FIG. 12. Estimated positions of Eddy 3 (solid dots) with circles indicating range of acoustic influence of Eddy 3 for specific dates of SOFAR float positions and sound transmission paths between 5 July and 11 September 1975. 
On 1 August, the large signal level designated $M$ from float 4 (see Fig. 4) was located about halfway between the caustic zones for the case of no eddy. The transmission path on this date grazes the outer boundary used to define Eddy 3 as shown in Fig. 12. On 12 August, float 4 produced the highest peak level, $N$ (see Fig. 4) and again the transmission path passed through the edge of Eddy 3. On 11 September, float 4's signal level was also high, (see peak $\Sigma$ in Fig. 4) and the float was again located between the caustic zones that were calculated for the case when no eddy is present. On this date, the transmission path passed through Eddy 3 much closer to the eddy center shown in Fig. 12. Note that peak $\Sigma$ in Fig. 4 is much lower in level than peak $N$.

It is interesting to examine the sound transmission paths in relation to the eddy at the times when the signal levels decreased following the high levels that occurred about 10 August for float 1 and 23 August for float 4. Using the same assumptions as in Fig. 12 for the eddy, one observes that the closest distance the transmission path comes to the eddy center, for both cases, is about $75 \mathrm{~km}$. This distance is indicated in Fig. 13 by the cross hatched bar from the eddy center that is perpendicular to the transmission path. This distance is where the gradual skirt in the temperature section of Fig. 11 abruptly changes to the inner core region of the eddy. In Fig. 13, the subsequent movements of the eddy and the floats can be seen to bring the transmission path taken to be in a vertical plane between source and receiver even closer to the eddy center. One should expect that the strong refraction caused by the inner region of the eddy could disrupt the phase relationships between the ray paths thereby possibly explaining the large reduction of signal level shown in Fig. 4 on those dates. The signal level is also relatively low between peaks $\Sigma$ and $T$ for float 4 in September in Fig. 4. For the lowest point on $23 \mathrm{Sep}-$ tember, the transmission path again passed the eddy center by about $75 \mathrm{~km}$ as shown in Fig. 13. Linear in-

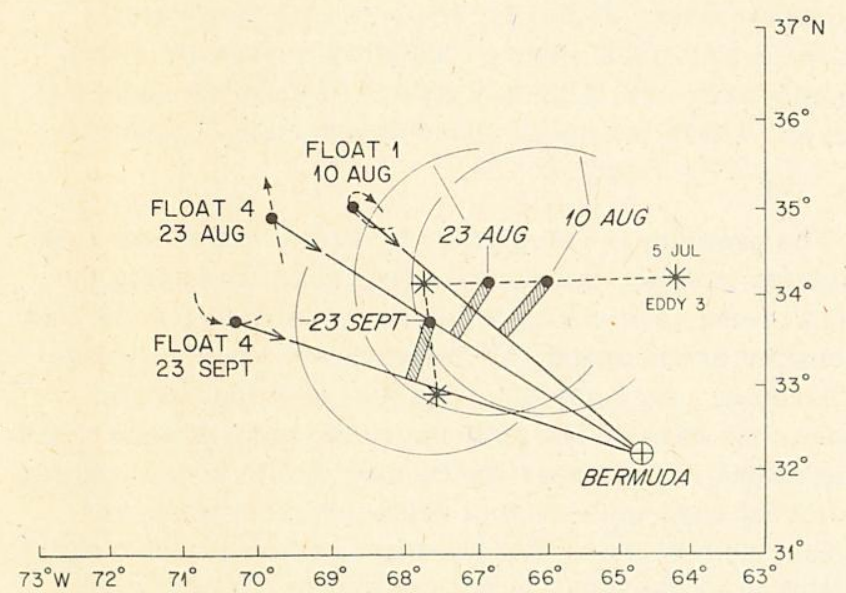

FIG. 13. Eddy 3 positions with circles indicating effective acoustic radius and SOFAR float signal paths for three dates marked by large decrease in received peak signal levels. Hashed bars indicate distance of closest approach of transmission paths to center of Eddy 3 . terpolation was used to estimate the position of Eddy 3 between the 11 September and 15 October positions.

It appears that by using a simple model for the eddy and its movements between known positions, that there exists a correspondence with observations of received signal fluctuations and shifts in the location of the transmission peaks which supports the hypothesis that Eddy 3 was responsible for much of the signal fluctuation. This does not rule out the possibility that a faster and more erratic motion of Eddy 3 with a shorter effective acoustic radius would not be more compatible with the data.

\section{THEORETICAL CONSIDERATIONS}

A practical side of theoretical underwater sound propagation problems concerns horizontal variations of a vertical channel because the dynamical process in ocean eddies produces major spatial and temporal changes in sound speed and currents. ${ }^{17}$ Beginning models for eddies for acoustics are being examined ${ }^{18}$ and some model studies ${ }^{19}$ and some data analysis ${ }^{20}$ that deals with Gulf Stream ring observations and propagation through eddies for a shallow sound source or a very deep receiver have been reported. But in our experimental study both the sound source and the receiver are near the depth of the minimum of sound speed in the main thermocline of the deep ocean, and this is a significant difference.

Most ray acoustics assumes an adiabatic process, namely, changes in a ray cycle are small over a ray cycle length. But for sound propagation through intense ocean eddies for the frequency of the SOFAR floats used here, this assumption is not appropriate as simple estimates will illustrate later. When no eddy exists along the transmission path, vertical ray focussing effects of the sound channel produce regularly spaced narrow caustic zones as in Fig. 3 that agree with observed transmission peaks. Qualitatively, the sound channel acts like a spatial series of converging lenses which focus the sound from the source over and over. The introduction of a Gulf Stream ring or cyclonic eddy places a lower sound speed region above the sound channel and this produces an equivalent divergent lens that shifts the caustic zones of Fig. 3 to greater range when the sound propagates through the eddy. The opposite effect will occur for an anticylconic eddy with clockwise circulation in which the dynamical process requires that higher sound speed water will extend downward in the central region of the eddy. Whether a caustic surface will shift to greater or shorter range depends on the location of the source and the kind of eddy. The computation of intensity for a source at the center of a cyclonic ocean eddy by Baer $^{11}$ (1980) shows the caustic position moves inward. In the present work, the source always remained away from the eddy centers and the cyclonic eddy would cause the caustic to shift to greater range. Consequent$1 y$, the calculation by Baer ${ }^{11}$ is only partially relevant, because neutrally buoyant SOFAR floats travel along density surfaces and therefore the floats should not be expected to move into the center of a Gulf Stream ring, instead they approximately advect along constant density contours with the current in nearly circular paths 
about the moving coordinates of the eddy center. ${ }^{6}$

As a specific example of the outward movement of a caustic zone by a cyclonic eddy neglecting advection of the sound by currents, consider the tranmission peak $M$ on 1 August, in Fig. 4. The float location for this peak is beyond the location of the caustic $B_{12}$ by about $18 \mathrm{~km}$. This is the caustic zone after 12 ray cycles as defined for the case of no eddy using the numbering system in the ray diagram of Fig. 3. According to Fig. 12 showing the inferred motion of Eddy 3, the sound transmission path at this time passes by the eddy center with a closest approach of about $167 \mathrm{~km}$. The isotherms of Fig. 8 and Fig. 11 for Eddy 3 will indicate a rise of $(900-800) \mathrm{m}=100 \mathrm{~m}$ from the edge of the eddy to this distance from the center. Out of the 12 ray cycles from the source to the receiver, the first 4 cycles have constant ray amplitude to the edge of the eddy and constant ray cycle length. The next four ray cycles increase in ray cycle amplitude per ray cycle by $\Delta Z=\frac{1}{4} \times 100 \mathrm{~m}$ $=25 \mathrm{~m}$ while the ray cycle length increases, and the next four ray cycles, both amplitude and length decrease per ray cycle by the same amount before reaching the receiver.

In view of this, the total outward shift of the focal zone, $B_{12}$, from its range when no eddy is present may be estimated using the very simple bilinear sound speed profile with gradients $G_{1}$ for the region above the axis and $G_{2}$ below the axis. After each ray cycle in the eddy, the upper layer characterized by sound speed gradient $G_{1}$ is displaced upward a distance, $\Delta Z=25 \mathrm{~m}$. This raises the sound channel axis and decreases the sound speed at the axis to $C_{1}=C_{0}-G_{2} \Delta Z$ for the first ray cycle within Eddy 3 . The reduction after $n$ cycles $n=1$ to 4 , is $C_{n}=C_{0}-n G_{2} \Delta Z$. We suppose that the horizontal change in the index of refraction is gradual enough that Snell's law holds, namely $\left(\cos \theta_{n} / C_{n}\right)=\left(\cos \theta_{0} / C_{0}\right)$ is a constant, where $\theta_{0}$ is the grazing angle of the ray in the profile outside of Eddy 3.

The accumulated distance the caustic zone moves out is thus

$$
\sum_{n=1}^{n=4}\left(G_{1}^{-1}+G_{2}^{-1}\right)\left(C_{n} \tan \theta_{n}-C_{0} \tan \theta_{0}\right) .
$$

For the reasonable values of $G_{1}$ and $G_{2}$, of $0.045 \mathrm{~m} / \mathrm{s} / \mathrm{m}$ and $0.012 \mathrm{~m} / \mathrm{s} / \mathrm{m}$, with $\theta_{0}=8^{\circ}$ and $C_{0}=1491 \mathrm{~m} / \mathrm{s}$, the above sum yields a shift of $8 \mathrm{~km}$. This is a large shift for so small a rise of the upper layer, $\Delta Z=25 \mathrm{~m}$ per ray cycle, but it is much less than the $18 \mathrm{~km}$ observed shift of the distance for transmission peak $M$, in Fig. 4. A more detailed approximation can be made using the Hirsch-Carter sound speed profile of Fig. 3, but this suggests a slightly smaller moveout of the focal distance. Larger shifts of the focal distance are possible if the transmission path passes closer to the center of the eddy. A value of $\Delta Z=50 \mathrm{~m}$ per ray cycle or a $200 \mathrm{~m}$ total rise in 4 ray cycles can explain the observed focal shift of $18 \mathrm{~km}$ for peak $M$ using Eq. (2). However, Fig. 11 indicates that the transmission path would have to pass within $80 \mathrm{~km}$ of the center of the eddy to have a $200 \mathrm{~m}$ rise of the isotherm. This distance of closest approach of the transmission path for float 4 on 1 August to the center of Eddy 3 in Fig. 12 is about half the distance of the effective acoustic radius, $167 \mathrm{~km}$, that was chosen for Eddy 3. It would follow that this close proximity of the eddy center to the transmission path for 1 August does not appear possible because of the position of Eddy 3 along the dashed line on 28 July shown in Fig. 12 and the positions of the two BT's, $T_{28}$ for that date which were related to the temperature distribution in Eddy 3 in Fig. 11. However, the argument for the choice of the effective acoustic radius of $167 \mathrm{~km}$ depends on the assumption of the simplified straight line dashed path of uniform motion of Eddy 3 between the two known locations of Eddy 3 on 5 July and 11 September because of environmental data during this period. The choice of $167 \mathrm{~km}$ for the effective acoustic radius is the distance normal to the transmission path for 24 July when the abrupt change in signal level occurred and the assumed point labeled 24 July along the dashed line path for Eddy 3 .

It is reasonable that a smaller effective acoustic radius for Eddy 3 would be a better choice, and to suppose the eddy moves about the region between this dashed line and the transmission paths of Fig. 12 in an effort to interpret all of the data consistently. This task is not attempted here because of the small amount of environmental data and the asymmetrical changing temperature structure of the moving ocean eddy.

Peak intensity computations for sound channel caustics using the parabolic equation approximation, Baer, ${ }^{11}$ indicate level changes of about $20 \mathrm{~dB}$. Earlier computations by Hirsch, ${ }^{21}$ Weston, ${ }^{22}$ for a symmetrical vertical sound profile are similar. Their computations agree in part with the observations presented here. But in an effort to understand the data of Fig. 4, we will refer primarily to the classic treatment of caustics in Brekhovskhih's "Waves in Layered Media."

Consider the theoretical reason for expecting caustic intensity peaks to decrease with range at $5 \mathrm{~dB}$ per distance doubled as observed in Fig. 4, which is only a little less than spherical spreading. We refer to Brekhovskhih's Eq. (38.64) for the potential on a caustic formed by a point source located in a constant sound speed layer overlying a boundary of an inhomogeneous layer, where the sound speed dependence is given by $n^{2}=\left(C_{0} / C\right)^{2}=1+a Z, Z<0$.

The problem is referred to by Brekhovskhik as a reflection caustic, and because the layer containing the source and receiver in which the caustic is formed has constant sound speed, all the rays are straight lines. Therefore, over any extended length of the caustic zone, the rays do not conform to the case of very slight curvature of rays near the turning points of the upgoing adjacent rays in the actual ocean problem above the sound channel axis. But the ray curvature over a short distance in the ocean is not critical to the argument given here because the intersection point of adjacent rays near the refraction caustic is formed by up and down going approximately straight line rays before and after their local turning points defined by their envelope curve. 
The potential at the caustic is a function of the ray angle with the horizontal at the axis or boundary, the horizontal distance $r$ from the source located at $Z_{0}$ above the boundary, to the caustic at height $Z$ above the boundary where the receiver is located, and to the parameter $a=d\left(n^{2}(Z)\right) / d Z \sim-(2 / c)(d c / d Z)$ which specifies the $Z$ dependence of the relative sound speed gradient in the inhomogeneous layer. The intensity at the caustic is the square of this potential, thus $\Psi^{2} \sim a^{2 / 3} / r$, in which $a r=K$, where $K$ is a constant, Eq. (38.61), which is dependent on the grazing angle of the ray with the inhomogeneous boundary. In decibels, one obtains by eliminating $a, 10 \log \Psi^{2}=10 \log \left(K / r^{5 / 3}\right)=(50 / 3)$ $\log (1 / r)=-16.7 \mathrm{~dB} /$ decade $=-5 \mathrm{~dB} /$ distance doubled.

Although the ray field of the caustic in Brekhovskhih's Fig. 162 is for only one layer, with $a=-(d c / d Z) / c$, it may be considered as the effective caustic field above the sound channel axis, in which the parameter $a^{\prime}$ applies above the axis and $a$ below it, by introducing an equivalent $a$, calculated from $\left(1 / a_{\text {eq }}\right)=(1 / a)+\left(1 / a^{\prime}\right)$, Porter. ${ }^{23}$ Moreover, the caustic ray field in Fig. 162 may be extended to any order of caustic found in the sound channel by merely increasing the height $Z_{0}$ of the source above the inhomogeneous layer in Fig. 162 without much change of the ray angle at the boundary. Hence $Z_{0}$ will increase in proportion to $N$ the order number, and there will be a corresponding increase in $r$. With these extensions in mind, it is clear why the inclination with the horizontal at height $Z$ of the caustic surface decreases with increasing order number.

Thus, if $\left(a Z_{0}\right)=0.1$ in Fig. 162 and $Z_{0}$ is $N$ times larger, then the corresponding position of the receiver, $Z$, is closer to the boundary of the caustic ray field shown, where the inclination of the caustic is clearly less. This effect may also be seen by looking at Fig. 3 for orders $N=1$ and $N=2$ in which the inclination of caustic $B_{2}$ is clearly less than that for $B_{1}$.

Mathematically, taking the ratio of Brekhovskhih's Eqs. (36.61) given as

$$
a r=4 \sin 2 \theta_{0} \cos ^{2} \theta_{0},
$$

and

$$
a\left(Z+Z_{0}\right)=4 \sin ^{2} \theta_{0} \cos 2 \theta_{0},
$$

one obtains $\left(Z_{0}+Z\right) / r \simeq\left(\theta_{0} / 2\right)$ so that the grazing angle $\theta_{0}$ decreases as one doubles the value of $Z_{0}$ and $r$. This decrease of the inclination with the horizontal of the caustic surface gives rise to a focusing, or vertical compression of the caustic surface and the interaction point of the up and down doing adjacent rays that form the caustic point. Thus the spreading of rays in this small zone is not that of a spherical surface and the usual $6 \mathrm{~dB}$ per distance doubled does not apply. This shows up in the ray analysis by Kinney and Pierce ${ }^{6}$ in that the caustic point for greater ray cycle order number or increasing range from the source moves closer to the upgoing ray's horizontal turning point.

In addition, there is a spatial oscillation of intensity of the caustic field given by the square of the Airy function shown in Fig. 160 of Brekhovskhih. Thus, as one moves a receiver through a caustic with increas- ing range, one expects to observe a rise to a maximum followed by a series of nearly equally spaced but decreasing maxima of intensity. A more exact theory of caustic formation includes an additional term, needed at distances behind the first maxima of the caustic that involves the derivative of the Airy function of diffraction theory in accord with Ludwig. ${ }^{24}$ See also Blatstein, ${ }^{25}$ Weinberg, ${ }^{26}$ and Spofford. ${ }^{27}$ Even neglecting this correction, the spacing between interference peaks behind the initial rise of the caustic with range may be estimated using Brekhovskhih's Eq. (38.65) for the parameter $t$ of the Airy function. Thus $t=-(\Delta r / 2)$ $\left(a k_{0}^{2} \tan ^{2} \theta_{0} \tan 2 \theta_{0}\right)^{1 / 3}$ and with $a=0.224 \mathrm{~km}, k_{0}=2 \pi f_{0} / C$ $=2 \pi 270 \mathrm{~Hz} / 1.4275 \mathrm{kms}^{-1}=1188.41 \mathrm{~km}^{-1}$, and $\theta_{0} \simeq 7^{\circ}$, the horizontal ray angle, one obtains $t=-\Delta r(5.30 / \mathrm{km})$. The first negative maximum of the Airy function occurs at $t=-3.2$, so the separation of interference peaks is $\Delta r \simeq 0.6 \mathrm{~km}$. Because the $B$ and $C$ caustics of the ray diagram, in Fig. 3 , are about $10 \mathrm{~km}$ apart, we may neglect for this discussion the added intensity from the $B$ caustic field formed from the downgoing cone of rays from the source to the intensity field of the $C$ caustic formed from the upward facing cone of rays emitted by the source.

By shifting peaks along the $5 \mathrm{~dB} /$ doubling distance trend lines in Fig. 4 to a common range, one finds the separation of $5 \mathrm{~dB}$ between the lowest signal level of float 4 (capital Greek letters) and those for float 1 (third trend line up) each corresponding to the period before July 24th. This difference in level is due to the difference in depth of the two floats which follows from the earlier theoretical discussion that increasing the vertical height of the source requires increasing the range, also, and this requires the caustic inclination to decrease, reducing the intensity at $Z$, the receiver height above the inhomogeneous layer. The estimate of the signal peak level change due to this source depth difference is straight forward. Thus, in the theory of a caustic for the case described above the squared potential $\psi^{2} \simeq a^{2 / 3} / r$, with $a r=K$ also has the condition $16 a\left(Z_{0}+Z\right)=(a r)^{2}$, where $Z_{0}$ for the source, $Z$ for the receiver, are distances measured from the horizontal boundary of the inhomogeneous layer. Thus $\Psi^{2} \sim a^{2 / 3} / r$ $=a^{2 / 3} a / a r=a^{2 / 3} a / a r=a^{2 / 3} a / K=K / 16\left(Z_{0}+Z\right)^{10 / 6}$. We assume the output of each source is the same, and accordingly, the signal level is given in decibels by 10 $\log \Psi^{2}=10 \log \left[(K / 16)\left(Z_{0}+Z\right)^{10 / 6}\right]$. Inserting the values $Z_{0}=0 \mathrm{~m}$ for float 1 because it is near the sound channel axis and $Z_{0}=200 \mathrm{~m}$, for float 4 , which was below the axis, and taking $Z=200 \mathrm{~m}$ for the receiver position, the calculated level difference is $-5 \mathrm{~dB}$ as observed in Fig. 4.

We mentioned earlier that the floats gradually sink because of creep, about $0.5 \mathrm{~m} /$ day so the ratio of $\left(Z+Z_{0}+0.5 \mathrm{~m} /\right.$ day) over 30 days gives $\left(200 \mathrm{~m}+Z_{0}\right.$ $+15 \mathrm{~m}$ ) for a float accounts for about $\frac{1}{2}-\mathrm{dB}$ decrease in received level. This cannot explain the $2-\mathrm{dB}$ difference between the trend lines clearly evident in Fig. 4 . But we point out that although the floats may change depth since they move on a constant density surface which may change depth, this vertical movement of the floats doesn't change the sound ray paths relative to the floats 
much because sound speed at the floats is a function of density, and therefore these paths tend to remain unchanged at the floats. This is not the situation at the receiver, however, which is fixed to the ocean floor. We note that the Panularus data, ${ }^{28,29}$ which consists of very long time series, now approximately 24 yrs long, of the depth variations of the $10^{\circ} \mathrm{C}$ isotherm near 900-m depth just south of Bermuda shows a conspicuous $\frac{1}{2}$ period near 1.5 to 1.8 months. Therefore most of the time these max and min extremes of an isotherm or density surface are located at the receiver depth. An estimate in change in depth of the isotherm is about $64 \mathrm{~m}$, thus one calculates the expected peak level change for those max and min depths from $16.7 \mathrm{log}$ $\left[\left(Z_{0}+Z+64\right) /\left(Z_{0}+Z\right)\right]=16.7 \log (264 / 200)=2 \mathrm{~dB}$.

The long period oscillations in Fig. 1 of level changes for Float 1 indicates a period of about 41 days, while for float 4 the period is near 34 days. Examination of north-south oscillations of Eddy 2 in Fig. 2, with its slow westward drift at the mean eddy speeds shown in Table I, indicates periods in this range. Consequently, the acoustic level fluctuations contain information about spatio-temporal fluctuations of Eddy 2. The radial component of the oscillations of float 4 as it circled around Eddy 2 while the eddy tended to move southwesterly, exhibits a period of about $1-\frac{1}{2}$ months. ${ }^{6}$ This period is also in the range of acoustic periods observed in the intensity fluctuations of the floats in Fig. 1. The density surface where the floats are neutrally buoyant lies in the inner region of eddies of this scale, which turns approximately in solid rotation. Besides this, measurements reported by Schmitz's ${ }^{33}$ and Owens et al.,${ }^{34}$ from long times series of moored current and temperature series indicate dominant periods in the region between Bermuda and the Gulf Stream from 1 to 3 months. Accordingly, it is no surprise that periods of acoustic intensity fluctuations from the SOFAR transmissions exhibit these periods. However, with only two floats and an incomplete environmental data set concerning ocean eddy locations it is not appropriate here to analyze the data for specific cause throughout the record.

We pointed out from an examination of Fig. 4 that sound transmission through ocean eddies shifts the focus to greater range and also increases intensity. If one takes into account the $5-\mathrm{dB}$ correction for the difference in source depths and corrects at $16.7 \mathrm{~dB}$ per decade the peak levels $H, \theta, \Sigma, \Phi, \nu, \lambda, M, N$, and $\Lambda$ which have been shifted to a common range, one may estimate the slope of the increase in peak level with horizontal focal shift to be about $30 \mathrm{~dB}$ per $40 \mathrm{~km}$ of shift.

The move out in range from the receiver of the two peaks $\theta$ and $H$ from float 4 during June, can be explained by the ray computations using Eq. (2) because the transmission path passed through Eddy 3 as was shown in Fig. 10. Also, this path passed within $75 \mathrm{~km}$ of the center of that eddy and Fig. 13 shows that this distance is the edge of the inner core of Eddy 3 where there is a relatively large change in the vertical profile of sound speed. This circumstance was associated with reduced levels of transmission peaks, and this could be the reason why these transmission peaks, $\theta$ and $H$, were of relatively low level compared to peaks that occurred after 24 July. In addition to this reason, the radial component of the float velocity was high at this time, $4 \mathrm{~km} /$ day, so that the float emission times, which were $6 \mathrm{~h}$ apart, might not have occurred near enough to the intensity maxima of the very narrow caustic zones to produce large transmission peaks. A detailed study of radial speeds of the floats from the receiver for all peaks (not presented here) indicate some correlation between high radial float speeds and low peak signal levels.

Some discussion of the problem of intensity computations near a caustic is presented by Baxter ${ }^{9}$ although he does not treat range variations. According to Fig. 1, there is a substantial increase in received peak levels from before to after 24 July (approximately 12-18 dB), however, only part of this large rise in level can be attributed to sound focusing by Eddy 3. A part results from change in float range. For instance, Fig. 4 shows that for float 1 the ranges of the float for peaks $\alpha, \mu$, and $\theta$ with no eddy along the sound path prior to 24 July were much greater than when the higher peak levels $\lambda, \mu$, and $\nu$ that occurred because the sound passed through the eddy. Using Fig. 4, after correcting for changes in range, the difference in level is about 7 to 8 $\mathrm{dB}$ for float 1. If $2 \mathrm{~dB}$ of this is attributed to periodic sound speed fluctuations at the hydrophone, then the effect of the eddy produces only about 6-dB enhancement in the signal level. This argument also applies to float 4 because if you note the rise in peaks $\Delta, M$, and $N$ in Fig. 1 it is clear from Fig. 4 that the float range also decreased and the level difference between peaks $I$ and $\Delta$ is about 7 to $8 \mathrm{~dB}$. Accordingly, the effect of focusing by Eddy 3 is closer to 6-8 dB. Theoretically, the effect of a cyclonic eddy, like Eddy 3, which increases the vertical excursion of adjacent rays that form the caustic and also increases their cycle length, as discussed in connection with Eq. (2), acts like a lens that may widen the very narrow cone of rays at the source by near a factor 2 in order to account for $\sim 6 \mathrm{~dB}$ increase in focal peak intensity. It is quite possible that the method of Baer,$^{11}$ which employs the parabolic approximation of the wave equation would show agreement with observed intensity levels of $\sim 6 \mathrm{~dB}$ if the transmission path for computation passed as close $80 \mathrm{~km}$ to the eddy center. We know this closer approach to the Eddy center was necessary to account for the focal shift in range observed for peak $M$ using Eq. (2). On the other hand, the usual procedure for intensity computations may not be valid because of the large relative change in sound speed over the distance of a ray cycle length that occurs for sound passing near the center of the eddy.

In the vicinity of caustics, intensity computation requires keeping account of rapid phase changes and the stationary phase method of ray theory is not valid. Milder ${ }^{35}$ points up the conditions when "action" is conserved in a channel that varies with range which depends on the amount of coupling between adjacent modes of a set being used to express the solution. Pierce ${ }^{36}$ 
formulated the problem when there is no mode coupling which enables one to expand a solution in the independent set of normal modes or eigenfunctions. If the coupling can be neglected, then changes in the sound speed with range are gradual enough so that ray cycle lengths change only a small amount from ray cycle to ray cycle. Milder's Eq. (42) which gives the wavelength condition for which normal modes are not coupled is $\lambda \gg\left(X^{2} / 2 \pi\right)[2(d c / d x) / c]$, with $c=c(x, z)$ for the sound speed and $X$ for the adjacent mode interference length. This length, $X$, in the wave formalism is the analog of the ray cycle length.

To see that for the frequency of the SOFAR floats mode coupling cannot be neglected for sound propagating through Eddy 3, consider Fig. 11. There is a change at $500-\mathrm{m}$ depth, of about $1{ }^{\circ} \mathrm{C}$ in moving from 300 to $150 \mathrm{~km}$ of the center of the eddy. The change of sound speed with temperature is $d c / d T \simeq 3 \mathrm{~m} / \mathrm{s} /{ }^{\circ} \mathrm{C}$, so $2(d c / d x) / c=(2 / 1.5 \mathrm{~km} / \mathrm{s})\left(3 \mathrm{~m} / \mathrm{s} /{ }^{\circ} \mathrm{C} \times 1{ }^{\circ} \mathrm{C} / 150 \mathrm{~km}\right)$ $=2.6 \times 10^{-5} / \mathrm{km}$. Using a ray cycle length $X \simeq 40 \mathrm{~km}$, one finds the wavelength should be much greater than $\left(X^{2} / 2 \pi\right) 2(d c / d x) / c=21 \mathrm{~m}$. Accordingly, the acoustic frequency $(C / \lambda)$, must be much lower than $70 \mathrm{~Hz}$ for coupling of adjacent modes to be neglected. Our source frequency was more than three times greater than this frequency. Moreover, if we considered a sound path passing to within $50 \mathrm{~km}$ of the eddy center from a source point at a distance of $150 \mathrm{~km}$, we find using Fig. 8 at 500-m depth that a temperature change would be $2{ }^{\circ} \mathrm{C}$. Thus $2(d c / d x) / c=8 \times 10^{-5} / \mathrm{km}$ and mode coupling cannot be neglected if the frequency is greater than $24 \mathrm{~Hz}$. At the source frequency of $270 \mathrm{~Hz}$, it is clear that "action" is not conserved as the sound path penetrates the core of the eddy to $50-\mathrm{km}$ radius.

How to handle the mode coupling in an acoustic propagation problem through intense large size eddies is essential. Chwieroth, et al.,${ }^{37}$ developed an exact mathematic approach to the case of mode coupling for a parabolic dependence of the index of refraction with depth $c^{2}=c^{2}\left(1-\alpha^{2}(r) Z^{2}\right)^{-1}$ for the case when the parameter $\alpha(r)$ decrease linearly with range at a constant rate. Although the parabolic dependence leads to a sinusoidal shape of ray paths which doesn't apply without modification to realistic sound channel conditions, it has been studied extensively in the literature, and can lead to large focusing peaks of near $20 \mathrm{~dB}$ as shown by Hirsch $(1965)^{21}$ even when no variations with range is considered.

Their work closely shows that even a small amount of coupling between modes can cause significant energy transfers between modes as range increases in a range dependent sound speed situation. This character of the problem cannot be neglected in sound channel propagation over long distances through intense ocean eddies. As more and more modes are required because of their coupling and the long ranges involved, practical computations become more difficult to manage unless the method of Baer ${ }^{11}$ provides satisfactory agreement. In a modified ray theoretical approach, the problem of computing rays and the intensity near a caustic was treated by Weinberg and Burridge (1974). ${ }^{38}$
Their work concerns the treatment of effects of horizontal gradients and can be shown to lead to some conclusions which are similar to those indicated above. But two-dimensional horizontal refraction is usually neglected on the basis that the radius of curvature of horizontal refraction is so large.

\section{CONCLUSIONS}

The conclusion that ocean eddies can produce large enhancements of sound transmission at caustic regions near the main sound channel can be made entirely on the basis of the empirical observations presented in the figures. The data also demonstrates that these narrow focal regions may be shifted considerable distances when the sound transmission path traverses a large cyclonic ocean eddy. Approximate ray computations do show that near sound channel axis caustic zones can be shifted to greater ranges because of transmission through a cyclonic eddy. If the sound path lies in a vertical plane between source and receiver and the path passes close to the eddy center $(\sim 80 \mathrm{~km})$, then a calculated shift can be as large as the observed shift for peak $M$ of $18 \mathrm{~km}$. But this indicates that the effective acoustic radius assumed for Eddy 3 of $167 \mathrm{~km}$ shown as a circle around the center in some figures may be too large by a factor of nearly 2. A shorter effective acoustic radius for the Eddy implies that Eddy 3 moved in a much more erratic path during its trip between the 5 July and 11 September positions of Fig. 2, instead of along the dashed straight line assumed in the analysis.

The observations in Fig. 4 exhibits a peak intensity falloff with range of $-5 \mathrm{~dB}$ per distance doubled and this agrees with the theory of caustics. The data exhibit several levels of intensity that have the above rate, and the separation of these levels can be explained from the theory of caustics to result from the difference in depths of the SOFAR floats and changes of the height of the receiver relative to the sound channel axis. The latter changes occur because of vertical thermocline oscillations. Not enough environmental information was available to render a detailed account of every peak signal recorded.

It is fun to point out that the separation of observed levels in Fig. 4 that arises from float emissions which propagate in a sound channel suggests a striking parallel to quantum levels in potential well problems of quantum mechanics. The analogy of acoustic wave guide theory and quantum wave theory has often appeared in the literature..$^{35}$

Computations of intensity levels due to transmission through strong cyclonic eddies may be feasible using; the parabolic equations approximation of the wave equation, Baer ${ }^{11}$; however, computations appropriate to the configuration in the experiment described here that will allow comparison with the data have not been reported in the literature. There are also some theoretical questions concerning whether changes per ray cycle are gradual enough to permit the more usual calculation of caustic intensities for rays that pass through regions of large horizontal variations of sound speed, such as occur in intense eddies. Nevertheless, 
the experimental results provide further support for continuing efforts to use acoustical signals, generated near the sound channel axis and recorded by receivers at large distances also located near the axis, for the purpose of locating ocean eddies. This possibility is one of the objectives of "acoustical oceanography." LaCasce and Beckerle ${ }^{39}$ in 1975 reported some conclusive experimental evidence that the extraction of temporal and spatial sound speed information was possible from travel time information using SOFAR channel signals, and they recommended a practical approach to accomplish this that would employ deep moored pulsed transmitters or a sequence of explosive charges. Recent work of Munk and Wunsch ${ }^{40}$ (1979) described a computational approach to the inverse process of extracting this information about spatial and temporal sound speed variations from the travel time measurements of signals that traverse a field of ocean eddies to arrive at receivers distributed around the boundaries of the ocean. But in view of the character of the observations in Fig. 4, we advance the possibility that much information about ocean gyres and eddies may be obtained from signal processing the emissions of sounds from numerous SOFAR floats strewn throughout the ocean. This appears to be a practical approach to oceanography which has considerable similarity to learning about galaxies in space from pulsers and other sources of radio emissions in the heavens using the field of study known as "radio astronomy."

\section{ACKNOWLEDGMENTS}

The authors acknowledge support from the office of Naval Research Code 480 for part of this study under Contract N00014-74-C-0262-NR083-004. Appreciation is extended to Earl Hayes and George Frisk for helpful comments in reviewing the manuscript. Dr. Earl Hayes conceived and initiated the acoustical measurements program. The analysis of oceanographic observations by student Andrew Jessup was particularly helpful and timely. The importance of the contributions of R. E. Cheney was given throughout the text, but several colleagues at the Institution here also provided valuable oceanographic data. Bathythermographic data from the Fleet Numerical Weather Central in Monterey, California, obtained from ship reports were particularly valuable in analysis. Their positions are shown in Fig. 2.

\section{APPENDIX A: SUMMARY OF DATA ANALYSIS- TRACK OF SOFAR FLOAT 2}

Information about the location of SOFAR float 2, particularly during the period of the large rise in signal levels from all floats about 24 July in Fig. 1 is important (although not crucial to the validity of the hypothesis that Eddy 3 produced the enhanced signals. The hypothesis is established from analysis of floats 1 and 4 for which the position data was excellent. It was coincidental that float 1 and float 4 were on the same bearing at the time of the large signal rise. It might be a bit much to expect to find float 2 near the same bearing about that time. Therefore the limited data available for float 2 positions were studied independently by 4 persons (including R. E. Cheney). The results are summarized in Fig. A1.

Two known fixes (acoustic ranging) are shown as bold $X$ 's for 27 March and 13 April. The float was moving eastward at $0.67 \mathrm{~km} / \mathrm{h}$ just to the south of the trace at the sea surface of the Gulf Stream obtained by satellite for 11 May 1975. After 13 April the acoustic data from float 2 only provided one range circle and occasionally data indicating its speed and whether it was moving toward or away from another hydrophone in deep water off the coast of the U.S.

Assuming the float continued to move eastward at speed $0.67 \mathrm{~km} / \mathrm{h}$ and using a range for 2 May from the hydrophone near Bermuda we estimate its position at the large open circle in the region of uncertainty for 2 May. Between 2 May and 9 May, the float increased its range from the hydrophone off Bermuda at speed $0.74 \mathrm{~km} / \mathrm{h}$. If it were at the position of the open circle on 2 May, it would have reached the region of the cross hatched zone north of the Gulf Stream labeled 9 May as shown by the arrow. Another possibility is that after 13 April it moved eastward at a higher speed reaching the extreme eastward position of the zone for

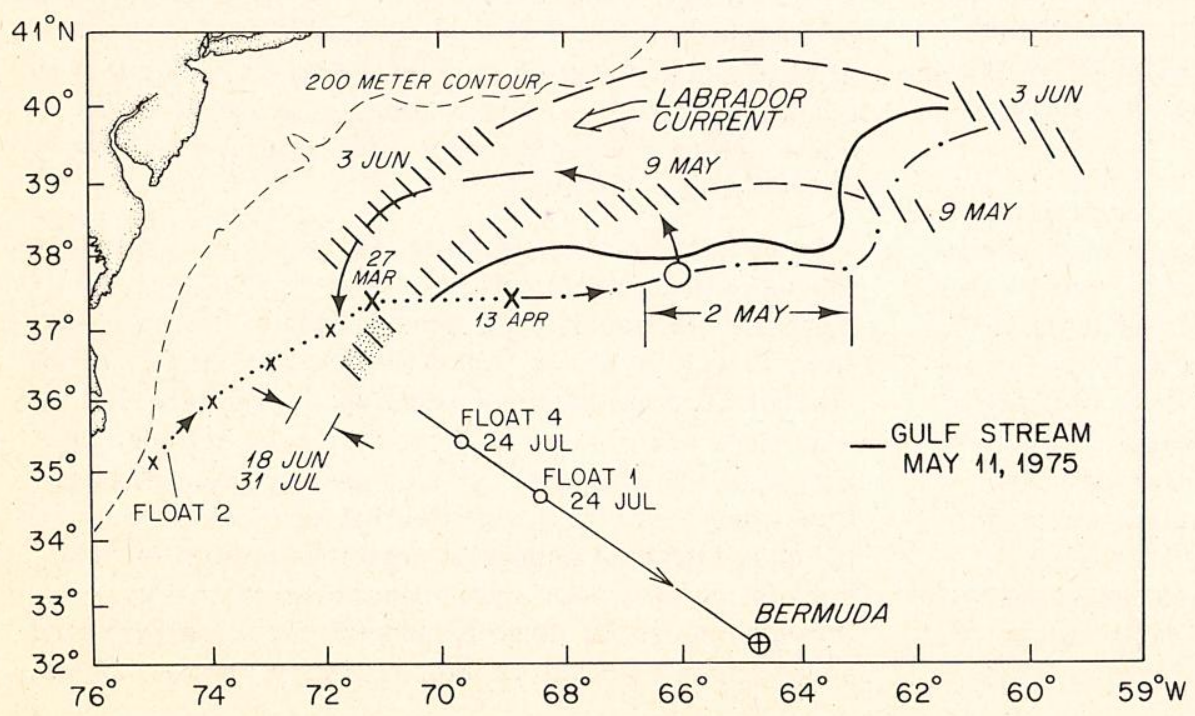

FIG. A1. Measured positions and interpretation of the locations of SOFAR float 2 during 1975. 
2 May and then moved northward to the position for 9 May. In this case it would have followed along the Gulf Stream path and moved northward paralleling the Gulf Stream as it bends northward there. After that it would have reached the known range for 3 June shown at the eastern portion of Fig. A1. We reject this path for float 2 because the average drift speed required between 13 April and 2 May is computed to be $1.2 \mathrm{~km} / \mathrm{h}$. This is almost twice the speed it had between $27 \mathrm{March}$ and 13 April. It is very unlikely that average flow speeds this high extend as deep as $1200 \mathrm{~m}$-the depth of float 2. A drift speed of $1.2 \mathrm{~km} / \mathrm{h}$ was observed in the motions of a float (float number 3 ) at $750-\mathrm{m}$ depth parallel to the Gulf Stream (see Fig. 2, Cheney et al. ${ }^{6}$ ). Accordingly, we examined the sketchy position data under the supposition that the float moved northward at the large open circle crossing beneath the Gulf Stream as shown in the figure. It is not at all unreasonable for a SOFAR float to be caught in a northward flow of an eddy beneath the Gulf Stream. Although much needs to be understood about Gulf Stream meanders, it is possible for the meanders to move faster than the current itself. Thus a current jet may cross the position of the float without causing much change in the floats average speed. As it moved northward it would eventually move with the westward and southwestward flow of the Labrador Current. This would bring it into the known range of the shaded zone for 3 June. Its westward drift speed of approximately $0.6 \mathrm{~km} / \mathrm{h}$ during this period is not unreasonable for the Labrador Current. After 3 June there were six range fixes from one hydrophone on 18 June, 2 July, 6 July, 31 July, 19 August, and 10 September. Its location in range between 18 June-31 July is shown in Fig. A1. This range interval is close to the Gulf Stream if the float is in the vicinity of the bearing of floats 1 and 4 on 24 July. On 6 July, float 2 moved unusually fast toward the northwest $(\sim 1.5 \mathrm{~km} / \mathrm{h})$. The only reasonable explanation for this high speed is that it was caught up by the Gulf Stream for that date. We therefore consider it plausible that float 2 was somewhere in the dark shaded area in Fig. A1 about the time of the large signal level increase shown in Fig. 1. This position is about twice as far from the hydrophone as float 1 on 24 July and supports the overall interpretation of the acoustic data given in the text.

${ }^{1} \mathrm{~T}$. Rossby and D. Webb, "Observing abyssal motions by tracking swallow floats in the SOFAR channel," Deep-Sea Res. 17, 359-365 (1970).

${ }^{2}$ T. Rossby, A. D. Voorhis, and D. Webb, "A quasi-Lagrangian study of mid-ocean variability using long range SOF AR floats," J. Mar. Res. 33 (3), 355-382 (1975).

${ }^{3}$ H. J. Freeland, P. B. Rhines, and T. Rossby, "Statistical observations of the trajectories of neutrally buoyant floats in the North Atlantic," J. Mar. Res. 33 (3), 383-404 (1975).

${ }^{4}$ L. Baxter and C. Y. Yang, "Fluctuations of narrow-band sound amplitudes from long-range transmissions in the deep Atlantic Ocean," J. Acoust. Soc. Am. 58, 595-603 (1975).

${ }^{5}$ R. Cheney, W. Gemill, M. Shank, P. Richardson, and D. Webb, "Tracking a Gulf Stream ring with SOFAR floats," J. Phys. Oceanogr. 6, 741-749 (1976).

${ }^{6} \mathrm{R}$. Cheney, "Entrapment of SOFAR floats by Gulf Stream rings," Polymode News 31, Edit. C., pp. 1, 3, 4, Figs. 3,
4, 5, and 6 (July 22, 1977), Woods Hole Oceanographic Institution (unpublished manuscript). Note: Eddy 2 is referred to as Ring D.

${ }^{7}$ A. Kinney and A. D. Pierce, "Caustics and the spreading of adjacent acoustic rays," J. Acoust. Soc. Am. Suppl. 1 65, F4 (1979).

${ }^{8} \mathrm{P}$. Hirsch and A. Carter, "Mathematical models for the prediction of SOF AR propagation effects," J. Acoust. Soc. Am. 37, 90-94 (1965).

${ }^{9} \mathrm{~L}$. Baxter II, "Ray calculations of the ocean sound channels using a pocket programmable calculator and extended forms of the Hirsch-Carter mathematical model with tables of the incomplete Beta function," J. Acoust. Soc. Am. 65 (4), 10611065 (1979). For intensity computations see more extensive presentation in W.H.O.I. Ref. Nos. 78-65.

${ }^{10} \mathrm{R}$. J. Urick, Principles of Underwater Sound (McGraw-Hill, New York, 1975), p. 384 (see Figs. 6.9, 6.14, 6.15).

${ }^{11}$ R. N. Baer, "Calculations of sound propagation through an eddy," J. Acoust. Soc. Am. 67, 1180-1185 (1980).

${ }^{12}$ L. Brekhovskihk, Waves in Layered Media (Academic, New York, 1960), p. 561, Ref. pp. 483-496.

${ }^{13}$ R. E. Cheney, "A census of rings in the Gulf Stream system," NAVOCEANO Technical Note 3700-44-76, U.S. Naval Oceanographic Office, Washington, D.C. 20373 (Jan. 1976).

${ }^{14}$ N. Hogg, E. Katz, and T. Sanford, "Eddies, islands, and mixing," J. Geophys. Res. 83 (C6), 2921-2938 (1978). Note: Fig. 1b shows sections through Eddy 2 and Eddy 3. Their Ring $\mathrm{A}$ is our Eddy 3.

${ }^{15}$ M. S. McCartney, L. V. Worthington, and W. J. Schmitz, Jr., "Large cyclonic rings from the northeast Sargasso Sea," J. Phys. Oceanogr. 83 (C2), 901-914 (1978).

${ }^{16} \mathrm{P}$. J. Hebert, "Atlantic hurricane season of 1975 ," Weatherwise 29 (1), 4, Fig. 1 (1976).

${ }^{17}$ G. R. Flierl, J. Phys. Oceanogr. 7, 365-379 (1977).

${ }^{18}$ R. F. Henrick, W. L. Siegmann, and M. J. Jacobson, J. Acoust. Soc. Am. 62, 860-870 (1977)..

${ }^{19}$ N. L. Weinberg and X. Zabelgogezcoa, "Coherent ray propagation through a Gulf Stream ring," J. Acoust. Soc. Am. 62, 888-894 (1977).

${ }^{20}$ A. C. Vastano and G. E. Owens, J. Phys. Oceanogr. 3, 470477 (1973).

${ }^{21} \mathrm{P}$. Hirsch, "Acoustic field of a pulsed source in the underwater sound channel," J. Acoust. Soc. Am. 38, 1018-1030 (1965).

${ }^{22} \mathrm{D}$. E. Weston, "Depth dependence of sound in a parabolic duct," 9th International Congress on Acoustics, Madrid, p. 656 (April-July 1977).

${ }^{23}$ R. P. Porter, "Dispersion of axial SOFAR propagation in the western Mediterranean," J. Acoust. Soc. Am. 53, 181 (1973).

${ }^{24}$ D. Ludwig, "Uniform asymtotic expansions at a caustic," Comm. Pure Appl. Math. 19 (1), 215-250 (1966).

${ }^{25}$ I. M. Blastein, "Comparison of ray theory and modified ray theory near a convergence zone caustic," J. Acoust. Soc. Am. 52 (3), Part 2, 1060-1061 (1972).

${ }^{26} \mathrm{H}$. Weinberg, "Application of ray theory to low frequency propagation," International Workshop on Low Frequency Propagation and Noise, Woods Hole, MA, 14-19 October 1974.

${ }^{27} \mathrm{C}$. W. Spofford, "Intensities of rays reflecting from curved and inclined surfaces in inhomogeneous," J. Acoust. Soc. Am. 51 (1), Part 1, 141 (1971).

${ }^{28} \mathrm{E}$. Schroeder and H. Stommel, "How representative is the series of Pannularus Stations of monthly conditions off Bermuda," in Progress in Oceanography Vol. 5, edited by Mary Sears (Pergamon, New York, 1969), pp. 31-39.

${ }^{29} \mathrm{C}$. Wunsch, "Bermuda sea level in relation to tides, weather, and baroclinic fluctuations," Rev. Geophys. Space Phys. 10 (1), 1-49 (1972)

${ }^{30}$ N. Hogg, "Observations of internal Kelvin waves trapped round Bermuda,"J. Phys. Oceanogr. (1980) (in press).

${ }^{31}$ W. J. Schmitz, "Observations of the vertical distribution of 
low frequency kinetic energy in the western North Atlantic," J. Mar. Res. 36 (3), 295-310 (1978).

${ }^{32}$ W. J. Schmitz and N. G. Hogg, "Observations of energetic low frequency current fluctuations in the Charlie-Gibbs fracture zone," J. Mar. Res. 36 (4), 725-734 (1978).

${ }^{33}$ W. J. Schmitz, "Weakly depth dependent segments of the North Atlantic circulation," J. Mar. Res. 38 (1), 111-133 (1980).

${ }^{34}$ W. B. Owens, J. R. Luyten, and H. L. Bryden, "Moored velocity measurements during the polymode local dynamics experiment," J. Mar. Res. (1980) (in press).

${ }^{35}$ D. M. Milder, "Ray and wave invariants for SOF AR channel propagation,” J. Acoust. Soc. Am. 46 (5), Part 2, 1259-1263 (1969).

${ }^{36}$ A. D. Pierce, "Extension of the method of normal modes to sound propagation in an almost stratified medium," J. Acoust. Soc. Am. 37 (1), 19-27 (1965).

${ }^{37}$ F. S. Chwieroth, R. D. Groves, A. Nagl, H. Uberall, and G. L. Zarwz, "Mode coupling in a sound channel with rangedependent parabolic velocity profile," J. Acoust. Soc. Am. 64, 1105-1112 (1978).

${ }^{38} \mathrm{H}$. Weinberg and R. Burridge, "Horizontal ray theory for ocean acoustics," J. Acoust. Soc. Am. 55, 63-79 (1974).

${ }^{39}$ E. L. LaCasce Jr. and J. C. Beckerle, "Preliminary experiment ot measure periodicities of large scale ocean movements with acoustical signals," J. Acoust. Soc. Am. 57, 966967 (1975).

${ }^{40} \mathrm{~W}$. Munk and C. Wunsch, "Ocean acoustic tomography: A scheme for large scale monitoring," Deep-Sea Res. 26A, 123-161 (1979). 


MANDATORY DISTRIBUTION LIST

FOR UNCLASSIFIED TECHNICAL REPORTS, REPRINTS, AND FINAL REPORTS PUBLISHED BY OCEANOGRAPHIC CONTRACTORS

OF THE OCEAN SCIENCE AND TECHNOLOGY DIVISION

OF THE OFFICE OF NAVAL RESEARCH

(REVISED NOVEMBER 1978)

1 Deputy Under Secretary of Defense

(Research and Advanced Technology)

Military Assistant for Environmental Science Room 30129

Washington, D.C. 20301

Office of Naval Research

800 North Quincy Street

Arlington, VA 22217

3 ATTN: Code 483

1 ATTN: Code 460

2 ATTN: 102B

1 CDR J. C. Harlett, (USN)

ONR Representative

Woods Hole Oceanographic Inst.

Woods Hole, MA 02543

Commanding Officer

Naval Research Laboratory

Washington, D.C. 20375

6 ATTN: Library, Code 2627
12 Defense Documentation Center Cameron Station

Alexandria, VA 22314

ATTN: DCA

Commander

Naval Oceanographic Office

NSTL Station

Bay St. Louis, MS 39522

ATTN: Code 8100

ATTN: Code 6000

ATTN: Code 3300

1 NODC/NOAA

Code D781

Wiscons in Avenue, N.W.

Washington, D.C. 20235 
UNCLASSIFIED $4 / 81$

CURITY CLASSIFICATION OF THIS PAGE(Whon Data Entered)

Acoustical signals at $270 \mathrm{~Hz}$ from SOFAR floats drifting in the region southeast of the Gulf Stream were recorded during most of 1975 from a near axis sound channel hydrophone near Bermuda. The amplitude levels received exhibit a large increase (12-18dB) commencing about 24 July, following a long period (March to July) of relatively lower peak level amplitudes. A major part of the increase can be attributed to the influence of a large cyclonic eddy (Gulf Stream ring) that passed slowly between the SOFAR floats and Bermuda. Such an eddy produces a large sound speed anomaly that extends to depths below the axis of the sound channel. On 24 July, two SOFAR floats were known to have approximately the same sound transmission path through the edge of the large eddy. The sound transmission peaks occur when no ocean eddy is between the SOFAR floats and the receiver. Their spacing shows they occur at regular refraction caustics in the sound channel. When the sound transmission path passes through an eddy, these transmission focal distances are shifted to greater range and the signal level may be greatly enhanced. The decrease of caustic peak intensities with range is $5 \mathrm{~dB}$ per double distance, and this agrees with theory. Several different levels of peak acoustic intensity occur and these result from two float depths and oceanic thermocline oscillations.

UNCLASSIFIED $4 / 81$

SECURITY CLASSIFICATION OF THIS PAGE(Whon Data Entered) 


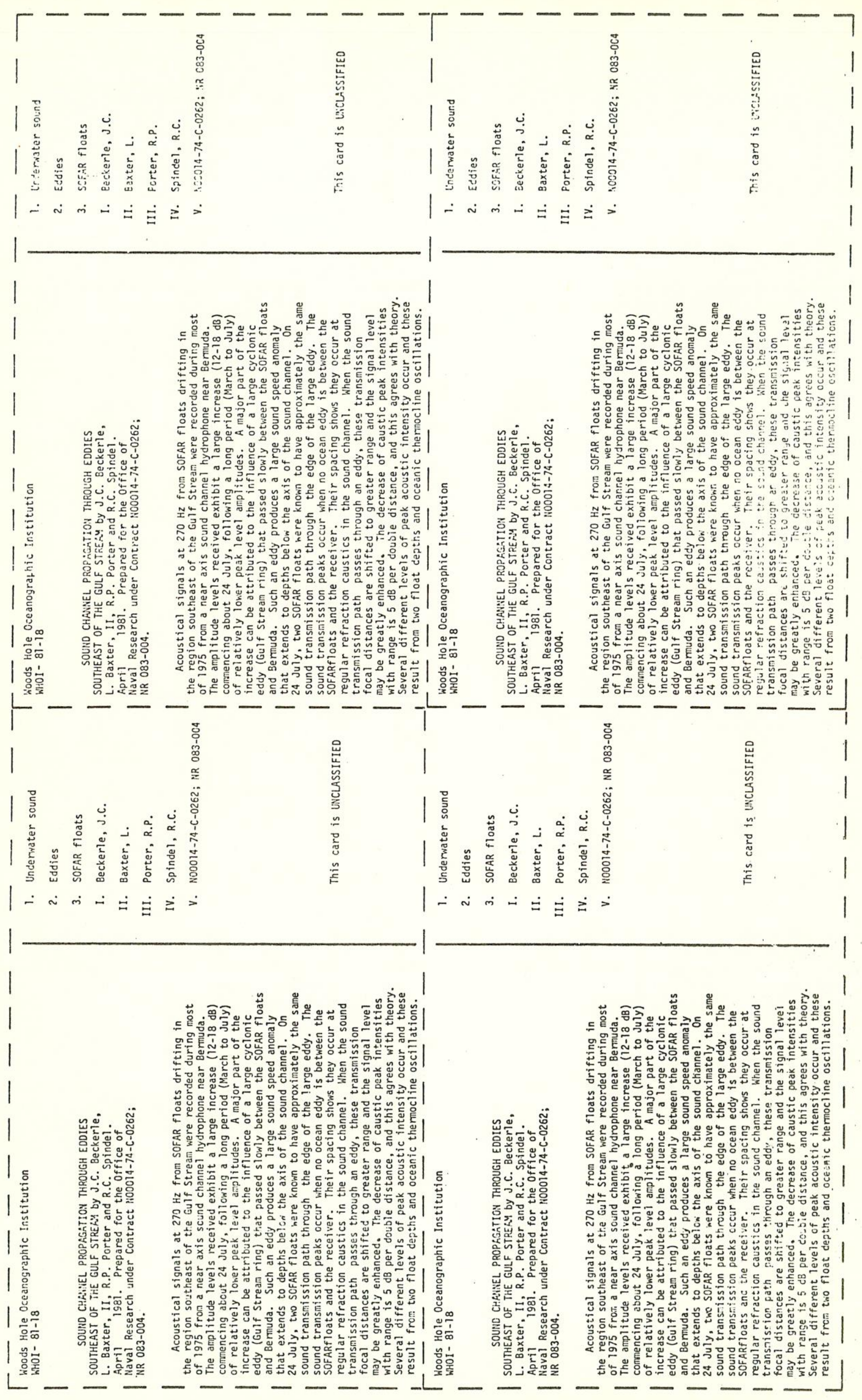

